\title{
Coniella vitis sp. nov. Is the Common Pathogen of White Rot in Chinese Vineyards
}

K. W. T. Chethana, Y. Zhou, W. Zhang, M. Liu, Q. K. Xing, X. H. Li, ${ }^{\dagger}$ and J. Y. Yan, ${ }^{\dagger}$ Institute of Plant and Environment Protection, Beijing Academy of Agriculture and Forestry Sciences, Beijing 100097, China; Beijing Key Laboratory of Environment Friendly Management on Fruit Diseases and Pests in North China, Beijing 100097, China; K. W. T. Chethana and K. D. Hyde, Centre of Excellence in Fungal Research, Mae Fah Luang University, Chiang Rai 57100, Thailand

\begin{abstract}
Grape white rot is a common disease and causes considerable yield losses in many grape-growing regions when environmental conditions are favorable. We surveyed grape white rot in five provinces in China and collected 27 isolates from diseased grape tissues. Multigene phylogenetic analyses of the internal transcribed spacer region (ITS1-5.8S-ITS2), the 28S large subunit of nuclear ribosomal RNA (LSU), partial translation elongation factor 1-alpha gene (TEF 1- $\alpha$ ), and partial histone 3 gene (HIS), coupled with genealogical concordance phylogenetic species recognition and

morphological observations, revealed that Coniella vitis sp. nov. and C. diplodiella are the causal agents of grape white rot in China. Koch's postulates were performed on Vitis vinifera cv. Summer Black in a greenhouse. These results confirmed the pathogenicity on grapes, as symptoms were reproduced, and also indicated significant variations in the virulence among $C$. vitis isolates. This work provides evidence that $C$. vitis is the main pathogen of grape white rot in China and also provides an optimized multigene backbone for resolving Coniella species.
\end{abstract}

Grape (Vitis vinifera L. and Vitis spp.), one of the most widely planted fruit crops, is mainly used as a fresh fruit and for wine production (Shao-Hua 2001). Due to its adaptability to diverse climatic conditions, grape cultivation has expanded around the world, reaching a total of 7.5 million hectares (OIV 2016). China is ranked second in the world for grape cultivation, with an area of 830,000 ha in 2015 (OIV 2016), whereas it is ranked first for grape production, with 11.5 million tonnes, producing $15 \%$ of the world's grapes (OIV 2014). Most of the grape production in China originates from $V$. vinifera cultivars, which are highly susceptible to fungal diseases (Li et al. 2008a; Magarey et al. 1993). In most Chinese grape-growing regions, the ripening period coincides with the heavy rainfall season, which is influenced by the East Asia monsoon climate (He 1999; Li et al. 2008a). The rainy season, together with warm summer temperatures, favors the spread of many diseases, resulting in a reduction in vine growth and grape yield and an increase in annual production costs (Úrbez-Torres et al. 2009).

Grape white rot has been reported as one of the main grape fungal diseases in China (He 1999; Li et al. 2008a) and results in an annual production loss of 16.3\% (He 1999). However, larger losses can be expected when extreme climatic events such as hailstorms cause wounds that favor the infection (Li et al. 2008a). Hence, the disease is also known as "hail disease"; however, hailstorms are not essential for development of the disease (Cortesi 2015). Wounds caused by climatic events, together with wounds caused by insects or other fungal diseases such as powdery mildew, become the entry points for pathogens (Cortesi 2015). Grape white rot is mainly caused by the pathogenic fungus Coniella diplodiella (Speg.) Petr. \& Syd. (Bisiach 1988; Crous and Carstens 2000; Crous et al. 2000; van Niekerk et al. 2004), which has also been reported in China (Changyuan et al. 1999). According to Crous and Carstens (2000), other Coniella Höhn. spp. such as $C$. fragariae (Oudem.) B. Sutton have also been reported from grapevines in South Africa. However, their ability to cause white rot has not been confirmed (Crous et al. 2000; Matthee and Thomas 1981; van Niekerk et al. 2004; Verbeek 1977). The genus Coniella, which was typified by $C$. fragariae, is cosmopolitan in distribution and consists of pathogens associated with foliar, fruit, stem, and root diseases in a wide

${ }^{\dagger}$ Corresponding authors: J. Y. Yan; E-mail: jiyeyan@vip.163.com and X. H. Li; E-mail: lixinghong1962@163.com

K. W. T. Chethana and Y. Zhou contributed equally to this work.

Accepted for publication 25 July 2017.

@ 2017 The American Phytopathological Society range of hosts (Alvarez et al. 2016; van Niekerk et al. 2004). In inoculation studies on grapevine, Tiedemann (1985) showed that $C$. diplodiella and $C$. fragariae cause white rot symptoms and that the latter exhibits the symptoms to a lesser degree. As mentioned by Cortesi (2015), pathogen normally overwinters as mycelium or pycnidia (containing 300 to 2000 conidia per gram of soil) in mummified berries, infected canes, and rachises that fall to the soil. This soil inoculum can remain viable for many years. Under wet or humid conditions, thousands of conidia are discharged from these pycnidia, and the soil-borne inoculum is distributed via rain, hailstorms, or farm equipment onto wound surfaces. Wounds act as entry points into berries, while on rachises and pedicels, infections occur via direct penetration (Cortesi 2015).

In the current study, we investigated Coniella spp. associated with white rot in China. Previous studies that identified $C$. diplodiella as the causal agent of grape white rot in China were based only on morphological identifications (Changyuan et al. 1999; Hu et al. 2010; Li et al. 2008b; Li 2012; Liu 2003). To date, no phylogenetic analyses have been combined with morphology to identify the white rot pathogens in China. Since species in this genus are morphologically similar, DNA-based approaches are required for their accurate identification, which is the basis for disease management.

\section{Materials and Methods}

Fungal isolates and morphological studies. Diseased grapevine samples were collected from the Beijing, Guangxi, Hebei, Henan, and JiLin provinces of China. Diseased tissue samples obtained from infected fruit, grape pedicels, rachises of clusters, and shoots, as well as from symptomatic leaves, were surface sterilized by washing with $1 \%$ sodium hypochlorite for $1 \mathrm{~min}, 70 \%$ ethanol for $1 \mathrm{~min}$, and finally in sterilized water three times prior to culture on potato dextrose agar (PDA) at $28^{\circ} \mathrm{C}$. If present, pycnidia were directly isolated from the surface of infected tissues. Single-spore isolation obtained pure cultures as described in Chomnunti et al. (2014). For long-term storage, cultures were transferred to sterilized filter paper at $-20^{\circ} \mathrm{C}$. Morphological observations were recorded as described in van Niekerk et al. (2004). Observations and photographs of the fungal structures were obtained using an Axio Imager Z2 photographic microscope (Carl Zeiss Microscopy, Oberkochen, Germany) and measurements were taken using ZEN PRO 2012 software (Carl Zeiss Microscopy). Forty conidial measurements were collected per isolate. As the species overlap in their conidial dimensions but differ in their conidial volume (Nag Raj 1993), the average conidial length:width ratios were calculated to further assist distinguishing the species. Growth rates and cultural characteristics were determined for all cultures after 5 days. The growth rate was calculated as the mean of two perpendicular measurements. Herbarium specimens 
were deposited in the Mae Fah Luang University (MFLU) herbarium, Thailand, and the Herbarium of Cryptogams (HKAS), Kunming Institute of Botany, China. All isolates were deposited in the culture collections at Mae Fah Luang University, Thailand (MFLUCC), the culture collection at Kunming Institute of Botany (KUMCC), China, and the Beijing Academy of Agricultural and Forestry Sciences (JZB), China. Following Jayasiri et al. (2015), Faces Of Fungi numbers were acquired.

DNA extraction, PCR amplification, and sequencing. Genomic DNA was extracted by modifying the protocol described in Guo et al. (2000). For the extraction, $500 \mathrm{mg}$ of fresh fungal mycelium were scraped from fresh cultures grown on PDA plates at $28^{\circ} \mathrm{C}$ for 3 to 7 days. Gene sequences were obtained from four gene regions, including the internal transcribed spacer region (ITS1-5.8S-ITS2), the $28 \mathrm{~S}$ large subunit of nuclear ribosomal RNA (LSU), partial translation elongation factor 1-alpha gene (TEF 1- $\alpha$ ), and partial histone 3 gene (HIS) using the specific primers shown in Table 1.

Polymerase chain reaction (PCR) was conducted in an Applied Biosystems Veriti Thermal Cycler according to White et al. (1990). The PCR conditions were as follows: initial denaturation for $3 \mathrm{~min}$ at $95^{\circ} \mathrm{C}$, followed by 34 cycles of denaturation for $30 \mathrm{~s}$ at $95^{\circ} \mathrm{C}$ and $30 \mathrm{~s}$ of annealing and $1 \mathrm{~min}$ elongation at $72^{\circ} \mathrm{C}$, and a final extension for $10 \mathrm{~min}$ at $72^{\circ} \mathrm{C}$. The annealing temperatures used in the cycling program were as follows: $52^{\circ} \mathrm{C}$ for LSU and TEF $1-\alpha, 55^{\circ} \mathrm{C}$ for ITS1-5.8S-ITS2, and $58^{\circ} \mathrm{C}$ for HIS. The PCR solution mixture was composed of $0.3 \mu \mathrm{l}$ of TaKaRa Ex-Taq DNA polymerase, $2.5 \mu l$ of $10 \mathrm{x}$ Ex-Taq buffer, $3.0 \mu \mathrm{l}$ of dNTPs, $1 \mu \mathrm{l}$ of genomic DNA, $1 \mu \mathrm{l}$ of each primer, and $16.2 \mu \mathrm{l}$ of $\mathrm{dd}_{2} \mathrm{O}$. Following the PCR amplification, products were visualized on $1 \%$ agarose gel under UV light using a Gel Doc XR+ Molecular

Table 1. Primers used in the study, with sequences and sources

\begin{tabular}{llllll}
\hline Gene & \multicolumn{1}{c}{ Product name } & Primer & Direction & \multicolumn{1}{c}{ Sequence $\left(\mathbf{5}^{\prime} \mathbf{- \mathbf { 3 } ^ { \prime }}\right)$} & Reference \\
\hline ITS1-5.8S-ITS2 & Internal transcribed spacer & ITS 1 & Forward & TCC GTA GGT GAA CCT GCG G & White et al. 1990 \\
& & ITS 4 & Reverse & TCC TCC GCT TAT TGA TAT GC & \\
HIS & Histone 3 & H3-1a & Forward & ACT AAG CAG ACC GCC CGC AGG & Glass and Donaldson 1995 \\
& & H3-1b & Reverse & GCG GGC GAG CTG GAT GTC CTT & Vilgalys and Hester 1990 \\
LSU & 28S large sub unit of nuclear & LR 7 & Forward & TAC TAC CAC CAA GAT CT & Rehner and Samuels 1994 \\
& ribosomal RNA & LROR & Reverse & ACC CGC TGA ACT TAA GC & Carbone and Kohn 1999 \\
TEF 1- $\alpha$ & Partial translation elongation & TEF1-728F & Forward & CAT CGA GAA GTT CGA GAA GG & \\
& factor 1- $\alpha$ & TEF1-986R & Reverse & TAC TTG AAG GAA CCC TTA CC & \\
\hline
\end{tabular}

Table 2. Isolates and sequences of Coniella species used in the study

\begin{tabular}{|c|c|c|c|c|c|c|c|}
\hline \multirow[b]{2}{*}{ Species } & \multirow[b]{2}{*}{ Culture collection $^{\mathbf{a}}$} & \multirow[b]{2}{*}{ Host } & \multirow[b]{2}{*}{ Country } & \multicolumn{4}{|c|}{ GenBank accession numbers ${ }^{b}$} \\
\hline & & & & ITS & Histone & LSU & TEF $1-\alpha$ \\
\hline Coniella africana & CBS $114133^{c}$ & Eucalyptus nitens leaf litter & South Africa & AY339344 & AY339309 & AY339293 & AY339364 \\
\hline Coniella crousii & NFCCI 2213 & Terminalia chebula fallen fruits & $\ldots$ & HQ264189 & $\ldots$ & $\ldots$ & . \\
\hline Coniella diplodiella & CBS $111858^{c}$ & Vitis vinifera stems & France & AY339323 & AY339297 & AY339284 & AY339355 \\
\hline Coniella diplodiella & CBS 166.84 & $V$. berlandieri $\times V$. riparia twig & Germany & AY339325 & AY339299 & AY339285 & AY339356 \\
\hline Coniella diplodiella & CBS 111857 & $V$. vinifera & South Africa & AY339331 & AY339305 & AY339286 & AY339357 \\
\hline Coniella diplodiopsis & CBS 590.84c & V. vinifera canes & Italy & AY339334 & AY339308 & AY339288 & AY339359 \\
\hline Coniella diplodiopsis & CBS 109.23 & V. vinifera & Switzerland & AY339332 & AY339306 & AY339287 & AY339358 \\
\hline Coniella erumpens & CBS $523.78^{c}$ & Rotten wood & Chile & KX833533 & $\ldots$ & KX833361 & KX833630 \\
\hline Coniella eucalyptigena & CBS $139893^{c}$ & Eucalyptus brassiana leaves & Malaysia & KR476725 & $\ldots$ & KR476760 & \\
\hline Coniella eucalyptorum & CBS $112640^{c}$ & $\begin{array}{l}\text { Eucalyptus grandis } \times \\
\text { E. tereticornis hybrid leaves }\end{array}$ & Australia & AY339338 & $\ldots$ & AY339290 & KX833637 \\
\hline Coniella eucalyptorum & CBS 114134 & $\begin{array}{l}\text { Eucalyptus camaldulensis ssp. } \\
\text { simulata }\end{array}$ & Vietnam & AY339339 & $\cdots$ & AY339289 & AY339361 \\
\hline Coniella eucalyptorum & CBS 111023 & Eucalyptus phyla & Mexico & AY339337 & $\cdots$ & KX833363 & AY339360 \\
\hline Coniella fragariae & CBS $172.49^{c}$ & Fragaria sp. stem base & Belgium & AY339317 & $\ldots$ & AY339282 & AY339352 \\
\hline Coniella fragariae & CBS 167.84 & V. berlandieri $\times$ V.riparia twig & Germany & AY339318 & $\ldots$ & EU754149 & KX833662 \\
\hline Coniella fusiformis & CBS $141596^{c}$ & Eucalyptus sp. leaves & Indonesia & KX833576 & $\ldots$ & KX833397 & KX833674 \\
\hline Coniella fusiformis & CBS 114850 & Eucalyptus pellita & Australia & KX833574 & $\ldots$ & KX833395 & KX833672 \\
\hline Coniella granati & CBS 252.38 & V. vinifera & Italy & AY339342 & $\ldots$ & AY339291 & AY339362 \\
\hline Coniella granati & CBS 814.71 & Punica granatum fruit & Turkey & KX833582 & $\ldots$ & AY408380 & KX833682 \\
\hline Coniella javanica & CBS $455.68^{c}$ & Hibiscus sabdariffai leaf spot & Indonesia & KX833583 & $\ldots$ & KX833403 & KX833683 \\
\hline Coniella koreana & CBS $143.97^{\mathrm{c}}$ & $\ldots$ & South Korea & KX833584 & $\ldots$ & AF408378 & KX833684 \\
\hline Coniella lanneae & CBS $141597^{c}$ & Lannea sp. leaves & Zambia & KX833585 & $\ldots$ & KX833404 & KX833685 \\
\hline Coniella limoniformis & CBS $111021^{c}$ & Fragaria sp. & South Africa & AY339346 & AY339310 & KX833405 & KX833686 \\
\hline Coniella macrospora & CBS $524.73^{c}$ & Terminalia ivoriensis stem & Ivory coast & AY339343 & $\ldots$ & AY339292 & AY339363 \\
\hline Coniella malaysiana & CBS $141598^{c}$ & Corymbia torelliana leaves & Malaysia & KX833588 & $\ldots$ & KX833406 & KX833688 \\
\hline Coniella musaiaensis & CBS 109757 & Hibiscus sp. & Africa & KX833589 & $\ldots$ & AF408337 & KX833689 \\
\hline Coniella nicotianae & CBS $875.72^{c}$ & Nicotiana tabacum & Jamaica & KX833590 & $\ldots$ & KX833407 & KX833690 \\
\hline Coniella nigra & CBS $165.60^{c}$ & Soil & India & AY339319 & $\ldots$ & KX833408 & KX833691 \\
\hline Coniella obovata & CBS 111025 & Leaf litter & South Africa & AY339313 & $\ldots$ & KX833409 & KX833692 \\
\hline Coniella paracastaneicola & CBS $141292^{c}$ & Eucalyptus sp. leaves & Australia & KX833591 & $\ldots$ & KX833410 & KX833693 \\
\hline Coniella paracastaneicola & СРC 25498 & Eucalyptus sp. & Australia & KX833592 & $\ldots$ & KX833411 & KX833694 \\
\hline
\end{tabular}

${ }^{a}$ CBS, CPC = Westerdijk Fungal Biodiversity Institute, Utrecht, Netherlands; JZB = Beijing Academy of Agriculture and Forestry Sciences Culture Collection, China; NFCCI = National Fungal Culture Collection of India, India.

${ }^{\mathrm{b}}$ Sequence data of internal transcribed spacer region (ITS1-5.8S-ITS2), histone gene (HIS), elongation factor 1- $\alpha$ (TEF1- $\alpha$ ), and large subunit (LSU).

${ }^{c}$ Ex-type, neo-type, and epitype cultures.

d Taxonomic novelties. 
Imager (BIO-RAD, USA) after ethidium bromide staining. DNA sequencing was done at the Sunbiotech Company, Beijing, China. The DNA sequences generated in this study were deposited in GenBank and their accession numbers are given in Table 2.

Phylogenetic analyses. Consensus sequences were generated using DNAStar v.5.1 and were analyzed using the National Center for Biotechnology Information (NCBI) search engine GenBank BLASTn. Fungal members closely associated with the new taxa, belonging to the same and different genera, were included in the analyses. Reference sequences used in previous studies were obtained from GenBank (Alvarez et al. 2016; Crous et al. 2012, 2014, 2015; Miranda et al. 2012; Rajeshkumar et al. 2011; van Niekerk et al. 2004) and listed in Table 2. Individual sequence datasets of ITS1-5.8S-ITS2, LSU, HIS, and TEF 1- $\alpha$ genes were aligned using the default settings of MAFFT v.7 (Katoh and Toh 2008; http://mafft.cbrc.jp/alignment/server) and improved manually where necessary using BioEdit (Hall 1999). Then, the aligned sequence datasets were concatenated manually.

Maximum parsimony (MP) analysis was performed in PAUP (phylogenetic analysis using parsimony) v.4.0b10 (Swofford 2002) using the heuristic search option with tree bisection-reconnection (TBR) branch swapping and 1000 random sequence additions. Ambiguous regions in the alignment were excluded, and gaps were treated as missing data. Stability of the trees was evaluated by 1000 bootstrap replications (Hillis and Bull 1993). Branches of zero length were collapsed, and all multiple parsimonious trees were saved. Descriptive statistics including tree length (TL), consistency index (CI), retention index (RI), relative consistency index (RC), and homoplasy index (HI) were calculated.
Differences between the trees inferred under different optimality criteria were evaluated using Kishino-Hasegawa tests (KHT) (Kishino and Hasegawa 1989)

The best model of evolution was determined by MrModeltest 2.2 for each gene (Nylander 2004). Maximum likelihood (ML) analysis was performed in raxmlGUIv.0.9b2 (Silvestro and Michalak 2010) with 1000 nonparametric bootstrapping iterations, using the general time reversible model (GTR) with a discrete gamma distribution. A tree with the final likelihood value of -12360.77 was selected as the best-scoring tree and the replicates were plotted relative to it.

Bayesian analyses were performed in MrBayes v.3.0b4 (Ronquist and Huelsenbeck 2003). The following models were applied: a symmetrical model with a discrete gamma distribution $(\mathrm{SYM}+\mathrm{G})$ for the ITS1-5.8S-ITS2 gene region, the Kimura 2-parameter model coupled with a proportion of an invariant site $(\mathrm{K} 80+\mathrm{I})$ for the LSU gene region, a general time-reversible model with a proportion of an invariant site (GTR + I) for the HIS gene region, and a general time-reversible model with a discrete gamma distribution coupled with a proportion of an invariant site $(\mathrm{GTR}+\mathrm{I}+\mathrm{G})$ for the TEF $1-\alpha$ gene region. The Markov Chain Monte Carlo sampling (BMCMC) analysis was conducted with four simultaneous Markov chains. They were run for $1,000,000$ generations; sampling the trees at every 100th generation. From the 10,000 trees obtained, first 2,000 representing the burn-in phase were discarded. Remaining 8000 trees were used for calculating posterior probabilities in the majority rule consensus tree (critical value for the topological convergence diagnostic set to 0.01) (Crous et al. 2006). Resulting phylogenetic trees were drawn using Treeview v.1.6.6 (Page

Table 2. (continued from previous page)

\begin{tabular}{|c|c|c|c|c|c|c|c|}
\hline \multirow[b]{2}{*}{ Species } & \multirow[b]{2}{*}{ Culture collection $^{\mathbf{a}}$} & \multirow[b]{2}{*}{ Host } & \multirow[b]{2}{*}{ Country } & \multicolumn{4}{|c|}{ GenBank accession numbers ${ }^{b}$} \\
\hline & & & & ITS & Histone & LSU & TEF 1- $\alpha$ \\
\hline Coniella peruensis & CBS $110394^{c}$ & Soil of rain forest & Peru & KJ710463 & $\ldots$ & KJ710441 & KX833695 \\
\hline Coniella pseudogranati & CBS $137980^{c}$ & Terminalia stuhlmannii & Zambia & KJ869132 & $\ldots$ & KJ869189 & $\ldots$ \\
\hline Coniella pseudostraminea & CBS $112624^{c}$ & Fragaria sp. & South Africa & KX833593 & $\ldots$ & KX833412 & KX833696 \\
\hline Coniella quercicola & CBS $904.69^{c}$ & Quercus robur leaf litter & Netherland & KX833595 & $\ldots$ & KX833414 & KX833698 \\
\hline Coniella solicola & CBS $766.71^{\mathrm{c}}$ & Soil & South Africa & KX833597 & $\ldots$ & KX833416 & KX833701 \\
\hline Coniella sp. & CBS 114006 & V. vinifera & India & AY339347 & AY339311 & AY339295 & KX833703 \\
\hline Coniella straminea & CBS 149.22 & Fragaria sp. & USA & AY339348 & AY339312 & AY339296 & AY339366 \\
\hline Coniella tibouchinae & CBS $131594^{c}$ & Tibouchina granulosa leaves & Brazil & JQ281774 & $\ldots$ & JQ281776 & JQ281778 \\
\hline Coniella tibouchinae & CBS 131595 & Tibouchina granulosa leaves & Brazil & JQ281775 & $\ldots$ & JQ281777 & JQ281779 \\
\hline Coniella vitis ${ }^{\mathrm{d}}$ & JZB3700001 ${ }^{\mathrm{c}}$ & $V$. vinifera & China & KX890008 & KX890033 & KX890083 & KX890058 \\
\hline Coniella vitis ${ }^{\mathrm{d}}$ & JZB3700002 & V. vinifera & China & KX889992 & KX890017 & KX890067 & KX890042 \\
\hline Coniella vitis $^{\mathrm{d}}$ & JZB3700003 & $V$. vinifera & China & KX889993 & KX890018 & KX890068 & KX890043 \\
\hline Coniella vitis ${ }^{\mathrm{d}}$ & JZB3700004 & $V$. vinifera & China & KX889994 & KX890019 & KX890069 & KX890044 \\
\hline Coniella vitis ${ }^{\mathrm{d}}$ & JZB3700005 & $V$. vinifera & China & KX889995 & KX890020 & KX890070 & KX890045 \\
\hline Coniella vitis $^{\mathrm{d}}$ & JZB3700006 & V. vinifera & China & KX889996 & KX890021 & KX890071 & KX890046 \\
\hline Coniella vitis ${ }^{\mathrm{d}}$ & JZB3700007 & $V$. vinifera & China & KX889997 & KX890022 & KX890072 & KX890047 \\
\hline Coniella vitis ${ }^{\mathrm{d}}$ & JZB3700008 & $V$. vinifera & China & KX889998 & KX890023 & KX890073 & KX890048 \\
\hline Coniella vitis ${ }^{\mathrm{d}}$ & JZB3700009 & $V$. vinifera & China & KX889999 & KX890024 & KX890074 & KX890049 \\
\hline Coniella vitis ${ }^{\mathrm{d}}$ & JZB3700010 & $V$. vinifera & China & KX890000 & KX890025 & KX890075 & KX890050 \\
\hline Coniella vitis ${ }^{\mathrm{d}}$ & JZB3700011 & $V$. vinifera & China & KX890001 & KX890026 & KX890076 & KX890051 \\
\hline Coniella vitis ${ }^{\mathrm{d}}$ & JZB3700012 & $V$. vinifera & China & KX890002 & KX890027 & KX890077 & KX890052 \\
\hline Coniella vitis ${ }^{\mathrm{d}}$ & JZB3700013 & $V$. vinifera & China & KX890003 & KX890028 & KX890078 & KX890053 \\
\hline Coniella vitis ${ }^{\mathrm{d}}$ & JZB3700014 & V. vinifera & China & KX890006 & KX890031 & KX890081 & KX890056 \\
\hline Coniella vitis $^{\mathrm{d}}$ & JZB3700015 & $V$. vinifera & China & KX890005 & KX890030 & KX890080 & KX890055 \\
\hline Coniella vitis ${ }^{\mathrm{d}}$ & JZB3700016 & $V$. vinifera & China & KX890004 & KX890029 & KX890079 & KX890054 \\
\hline Coniella vitis ${ }^{\mathrm{d}}$ & JZB3700018 & $V$. vinifera & China & KX890009 & KX890034 & KX890084 & KX890059 \\
\hline Coniella vitis $^{\mathrm{d}}$ & JZB3700019 & $V$. vinifera & China & KX890012 & KX890037 & KX890087 & KX890062 \\
\hline Coniella vitis $^{\mathrm{d}}$ & JZB3700020 & V. vinifera & China & KX890013 & KX890038 & KX890088 & KX890063 \\
\hline Coniella vitis $^{\mathrm{d}}$ & JZB3700021 & $V$. vinifera & China & KX890015 & KX890040 & KX890090 & KX890065 \\
\hline Coniella vitis ${ }^{\mathrm{d}}$ & JZB3700022 & $V$. vinifera & China & KX890016 & KX890041 & KX890091 & KX890066 \\
\hline Coniella vitis ${ }^{\mathrm{d}}$ & JZB3700023 & $V$. vinifera & China & KX890007 & KX890032 & KX890082 & KX890057 \\
\hline Coniella vitis ${ }^{\mathrm{d}}$ & JZB3700024 & $V$. vinifera & China & KX890010 & KX890035 & KX890085 & KX890060 \\
\hline Coniella vitis $^{\mathrm{d}}$ & JZB3700025 & $V$. vinifera & China & KX890011 & KX890036 & KX890086 & KX890061 \\
\hline Coniella vitis ${ }^{\mathrm{d}}$ & JZB3700026 & $V$. vinifera & China & KX890014 & KX890039 & KX890089 & KX890064 \\
\hline Coniella wangiensis & CBS $132530^{c}$ & Eucalyptus sp. & Australia & NR_111764 & $\ldots$ & NG_042686 & KX833705 \\
\hline Melanconiella sp. & CBS 110385 & Soil rain forest & Peru & KX833599 & $\ldots$ & KX833420 & KX833707 \\
\hline
\end{tabular}


1996). Sequences derived in this study were deposited in GenBank; alignments and trees were deposited in TreeBase (S20261).

Genealogical concordance phylogenetic species recognition analysis. The Genealogical Concordance Phylogenetic Species Recognition (GCPSR) model with a pairwise homoplasy index (PHI) test was used to analyze new species, their limits, and their most closely related neighbors as described by Quaedvlieg et al. (2014). The recombination level within phylogenetically closely related species was determined with the PHI test performed using SplitsTree4 (Huson 1998; Huson and Bryant 2006). The concatenated dataset (ITS1-5.8S-ITS2, LSU, HIS, and TEF 1- $\alpha$ ) was used for $C$. vitis and its sister taxa, C. diplodiella and $C$. diplodiopsis (Crous \& van Niekerk) L.V. Alvarez \& Crous. The relationships between these three species were visualized in splits graphs with both the Log-Det transformation and splits decomposition options. A pairwise homoplasy index below a 0.05 threshold $\left(\Phi_{\mathrm{W}}<0.05\right)$ indicated the presence of significant recombination in the dataset.

Pathogenicity test. Detached leaf inoculation. Young, healthy detached leaves of Vitis vinifera cv. Summer Black were collected from plants in a greenhouse and used for the pathogenicity tests. Six of the newly isolated species strains (JZB3700001, JZB3700006, JZB3700009, JZB3700012, JZB3700014, and JZB3700023) were selected. Surface sterilization was performed on leaves as follows: washed in $75 \%$ ethanol for $1 \mathrm{~min}$, then $10 \%$ sodium hypochlorite for $1 \mathrm{~min}$, followed by washing with distilled water three times. The experiment was conducted using five leaves per isolate (including one control), inoculated using two methods: nonwound and wound inoculation. The latter was performed on symmetrical halves of each leaf, by injuring the upper epidermal layer of the leaf, using a sterile needle. PDA plugs ( $5 \mathrm{~mm}$ diameter) with fungal mycelia (from 3-day-old culture) were inoculated on both the wounded and nonwounded sites of each of the leaves. Sterile agar plugs ( $5 \mathrm{~mm}$ diameter) were used as the control. All leaves were incubated in a moist chamber at $28^{\circ} \mathrm{C}$ with a $95 \%$ relative humidity, until symptoms appeared. Lesion lengths were recorded three days after inoculation. Once the symptoms appeared, Koch's postulates were confirmed by reisolation of the inoculated fungus and the identification was based on cultural and morphological characters.

Detached fruit inoculation. Pathogenicity tests were conducted on healthy young berries of uniform size in detached clusters, collected from $V$. vinifera $\mathrm{cv}$. Summer Black using the same isolates previously mentioned. Berries were collected at different growth stages, including pea size, green, and well-separated, and berries in closed bunches at veraison. These clusters were broken down into small clusters with their rachis intact. Berries were surface sterilized as mentioned before. The experiment was conducted using five small clusters per isolate (including one control), inoculated using two methods. For the wound inoculation, the epidermis was superficially wounded using a sterilized needle, but for the clusters at their formation stage, wounds were made on the rachis as the berries were of smaller size (diameter 4 to $7 \mathrm{~mm}$ ). One hundred $\mu$ l of conidial suspension $\left(10^{6}\right.$ spores/ $\left.\mathrm{ml}\right)$ from each of the isolates were microinjected using a sterile inoculator on to the wounds of the berries. For the nonwound inoculation, conidial suspensions were placed on the berries without making any wounds. Sterile water was used as the control. Each inoculated berry cluster was placed in a $12-\mathrm{cm}$-diameter petri dish. During the incubation period at $28^{\circ} \mathrm{C}$, wetted cotton swabs were placed in petri dishes to maintain humidity and plates were placed inside the incubator at $80 \%$ RH. Initial symptoms appeared 5 days after the inoculation. Finally, Koch's postulates were confirmed by reisolation of the inoculated fungus and the identification was carries out based on cultural and morphological characters. All inoculated leaves and berry clusters were autoclaved before being disposed.

Direct plant inoculation. Direct plant inoculations were conducted to determine whether the new species can cause the disease in a live plant, rather than detached plant parts. For this experiment, five young plants of $V$. vinifera $\mathrm{cv}$. Summer Black from the greenhouse were selected for inoculation and another five plants were used as controls. Only the holotype culture (JZB3700001) was selected for the pathogenicity assay. From each plant three new young leaves and three green shoots were wounded using a sterilized needle. The wound on the leaf was made by injuring the upper epidermal layer and the wound on the green shoot was made at the distal end using a sterilized needle. Wounded shoots and leaves were inoculated with $100 \mu l$ of spore suspension $\left(10^{6}\right.$ spores $\left./ \mathrm{ml}\right)$. For the control we used $100 \mu \mathrm{l}$ of sterilized water. These plants were maintained at 70 to $80 \%$ RH of and a temperature at $28^{\circ} \mathrm{C}$.

Data Analysis. One-way analysis of variance (ANOVA) was used to analyze data obtained from the pathogenicity tests at 5\% significance level. The analysis was implemented in the MINITAB statistical program v.16.0 (Minitab Inc., State College, PA). Normality tests of Shapiro-Wilk and Jarque-Bera were conducted for all datasets. The means of the different isolates were compared using Fisher's test at the $5 \%$ significance level.

\section{Results}

Isolation of fungi. Coniella isolates were obtained from various white rot-affected tissues, including infected fruit (directly from conidiomata), pedicels, rachises, shoots, and leaves. Twenty-five isolates were obtained from 20 diseased samples of $V$. vinifera cvs. Summer Black, and Centennial seedless grape, collected from Beijing, Guangxi, Hebei, Henan, and JiLin provinces.

Phylogenetic analyses. Single-gene phylogenetic analyses, optimized multigene phylogeny and species recognition. Sequences from 25 isolates from the current study and those generated in previous studies for the ITS, LSU, TEF 1- $\alpha$, and HIS gene regions (Alvarez et al. 2016; Crous et al. 2012, 2014, 2015; Miranda et al. 2012; Rajeshkumar et al. 2011; van Niekerk et al. 2004) were used to construct single-gene phylogenetic trees. These phylogenetic analyses consisted of 66 Coniella isolates obtained from various sources and different geographical locations. All the isolates from the current study clustered in a subclade within the $C$. diplodiella/C. diplodiopsis clade (see Figure 1). It was observed that ITS phylogeny separated single species from species complexes in the genus Coniella, and LSU phylogeny provided a higher taxonomic order for separation of the Coniella isolates. The TEF1- $\alpha$ alignment provided better separation between $C$. diplodiella, C. diplodiopsis, C. eucalyptorum (Crous \& M.J. Winf.) L.V. Alvarez \& Crous, C. wangiensis (Crous \& Summerell) L.V. Alvarez \& Crous, C. crousii (Raheshk. et al.) L.V. Alvarez \& Crous, C. obovata L.V. Alvarez \& Crous, and C. fragariae isolates. However, in all of these alignments, $C$. diplodiella, $C$. diplodiopsis, and the novel species introduced in this study clustered together. These isolates clustered into different clades when aligned using the HIS gene due to its high variability, caused probably by a high ratio of parsimony uninformative variable sites in the histone gene region ( 87 variable, parsimony uninformative positions) compared with phylogenetically informative changes (64 positions).

In addition to the single-gene trees constructed in the current study, most of the possible gene combinations were tested to obtain a better resolution for the identification of Coniella species. Among all of the alignment combinations, the best resolution with the highest bootstrap values was obtained when all loci were used for the analysis in the following order: ITS, LSU, HIS, and TEF $1-\alpha$. The combined dataset contained 66 sequences representing 30 taxa with Melanconiella sp. (CBS 110385) as the outgroup (Fig. 2). Similar multigene phylogenetic trees resulted from all the analyses, including MP, ML, and Bayesian. The parsimony analysis comprised 2877 total characters (585 in the ITS, 1189 in the LSU, 608 in the TEF $1-\alpha$, and 485 in the histone gene regions), including gaps. The concatenated alignment contained 558 parsimony informative characters, 238 variable and parsimony uninformative characters, and 2081 constant characters. The first of 1000 equally parsimonious trees is shown in Figure 2, which enabled the identification of the isolates to species level, with a better resolution than the single-gene analyses $(\mathrm{TL}=2643, \mathrm{CI}=0.514, \mathrm{RI}=0.739, \mathrm{RC}=0.380, \mathrm{HI}=0.486)$.

In the combined analysis, the 66 isolates grouped into different clades representing different taxa. In contrast to the single-gene analyses, the combined analysis revealed distinct separate clades for the C. diplodiella/C. diplodiopsis complex. The phylogenetic analyses provided good evidence that all of the isolates from the current study belonged to a new species, named $C$. vitis, which formed a clade that 
was well separated from $C$. diplodiopsis, with high bootstrap value $(\mathrm{MP}=100 \%, \mathrm{ML}=100 \%)$ and Bayesian posterior probability (1.00).

Genealogical concordance phylogenetic species recognition analysis. In order to determine evolutionary independence, the GCPSR concept was applied to the $C$. vitis dataset and its neighboring taxa. A pairwise homoplasy index ( $\mathrm{PHI}$ or $\Phi w$ ) below 0.05 provide evidence for the presence of significant recombination within a dataset. According to the GCPSR analysis, our dataset showed PHI of 1.0, indicating no significant genetic recombination between $C$. vitis and its sister taxa, C. diplodiella and C. diplodiopsis (Fig. 3). Hence,
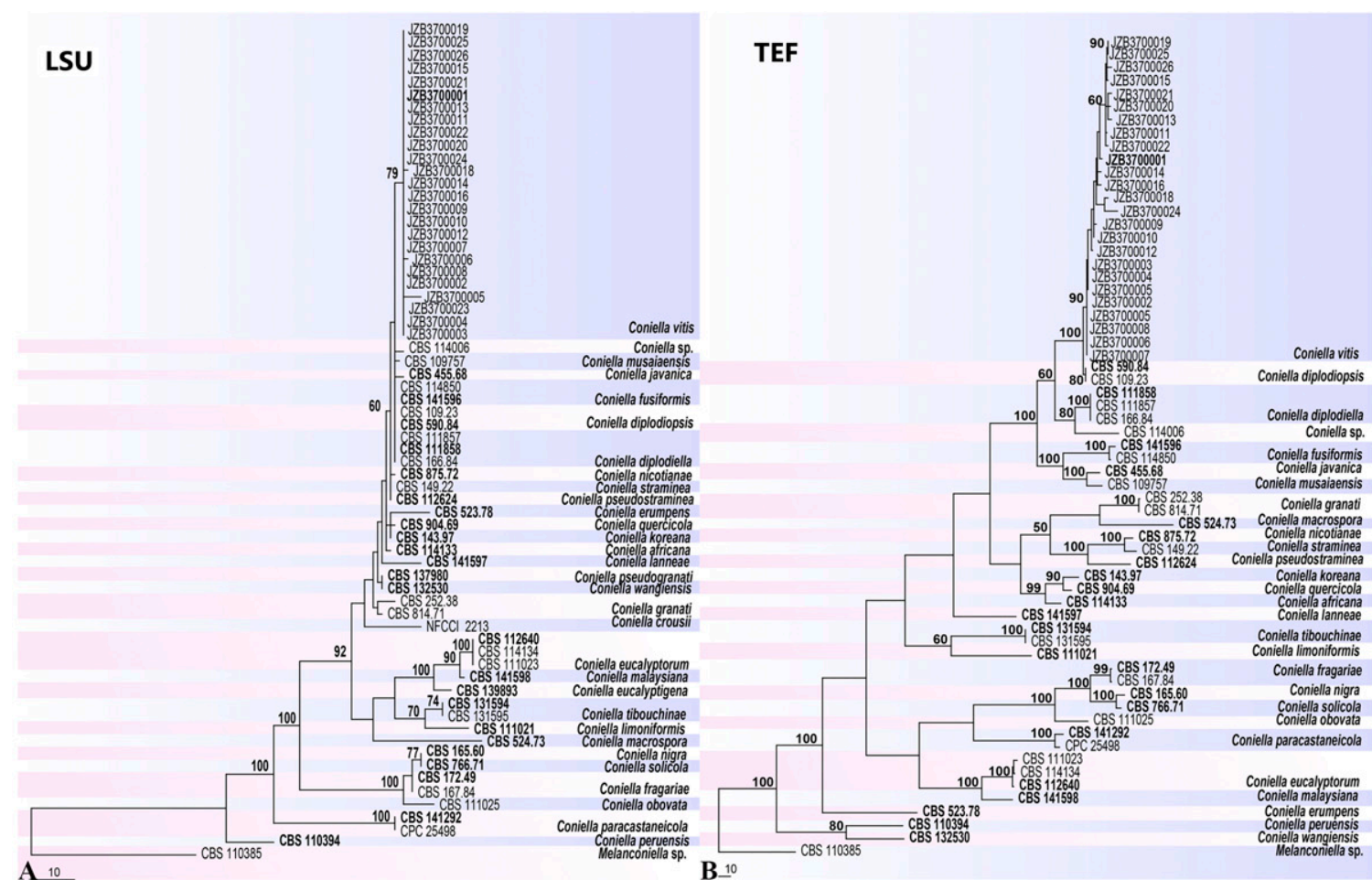

B 10
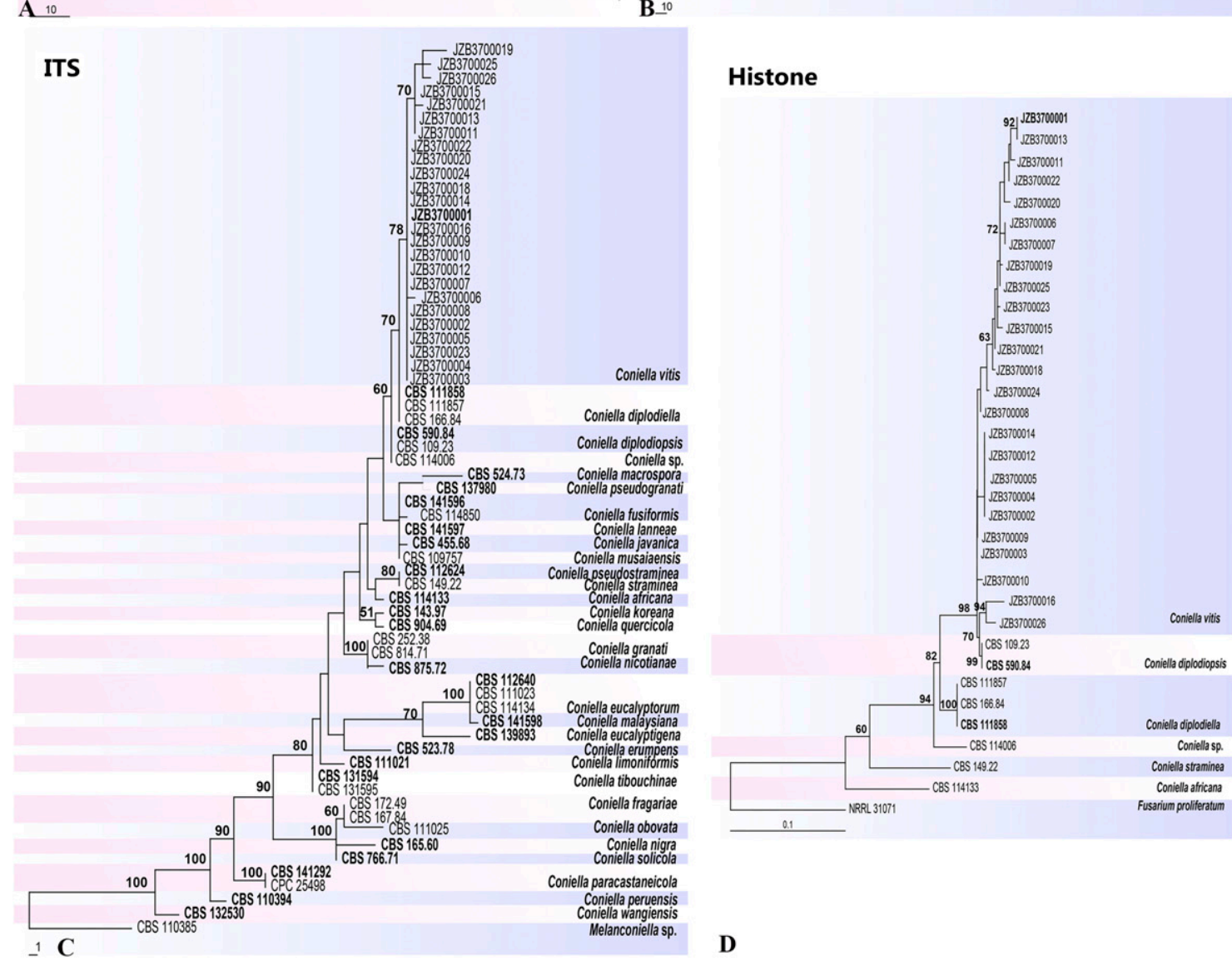

D

Fig. 1. Maximum likelihood analyses based on sequence data of single gene regions of Coniella species. A, 28S large subunit (LSU). B, Translation elongation factor 1- $\alpha$ (TEF1- $\alpha$ ). C, Internal transcribed spacer region (ITS1-5.8S-ITS2). D, Histone gene. Bootstrap support values greater than $50 \%$ are indicated near the nodes. The ex-types are in bold. Scale bars indicate 10 changes for LSU and TEF1- $\alpha$ genes, 1 change for ITS1-5.8S-ITS2, and 0.1 change for histone gene. The trees are rooted with Melanconiella sp. (CBS 110385) for all the genes, except for histone gene, which is rooted with Fusarium proliferatum (NRRL 31071). 
it is concluded that these three taxa were significantly different from each other. As we observed a high phylogenetic and pathogenic diversity among the newly introduced species, we applied the GCPSR concept to a dataset, consisting of only $C$. vitis isolates. The analysis resulted in a PHI below $0.05(\Phi w=0.0001207)$ for all the $C$. vitis isolates, indicating a significant recombination among the $C$. vitis isolates. This confirms that all of these isolates belong to the same species.

Taxonomy. Isolates associated with white rot of $V$. vinifera clustered in a distinct clade in the multigene phylogeny (Fig. 2). The new species described here, Coniella vitis (Fig. 4), is closely related to C. diplodiopsis, which was originally described as another pathogen

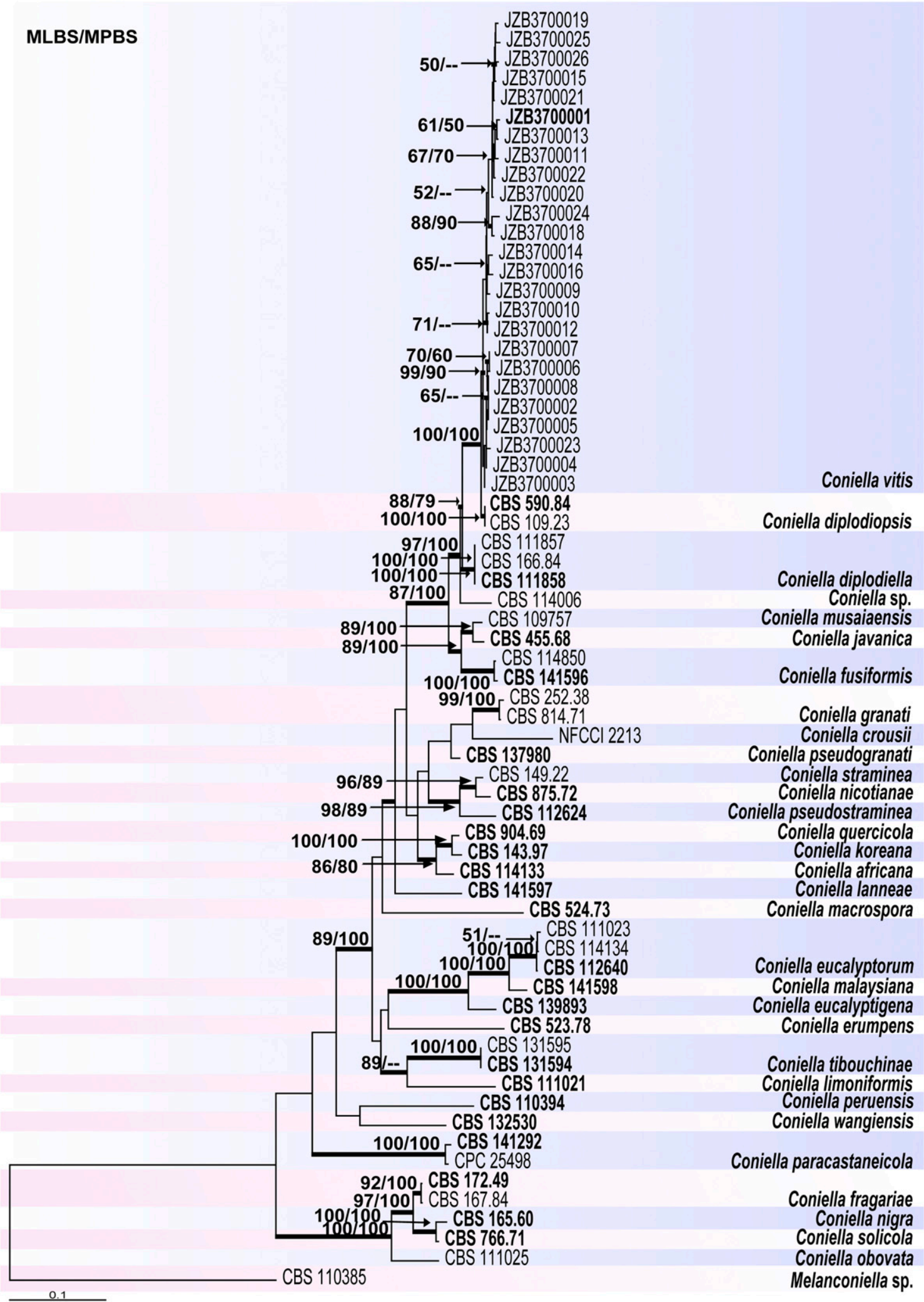

Fig. 2. Maximum likelihood analysis phylogram based on combined ITS, LSU, histone, and TEF1- $\alpha$ sequence data of Coniella species. Maximum likelihood and parsimony bootstrap support values greater than $50 \%$ are indicated near the nodes, and branches with Bayesian posterior probabilities greater than 0.95 are given in bold. The ex-types are in bold. The scale bar indicates 0.1 changes. The tree is rooted with Melanconiella sp. (CBS 110385). 
associated with $V$. vinifera in Italy and Switzerland (van Niekerk et al. 2004).

Disease symptoms identified in the field. During this study, symptomatic vines were observed in several vineyards in different provinces. Initially, infected immature berries change color from pale green to pinkish and then dark brown. When the observations were made at the end of summer, in almost all of the vineyards the disease has passed its initial stage. However, only five to six observations of immature dark brown berries were made in several diseased clusters. All the observed diseased vines were carrying completely or partially desiccated clusters. During this process, berries lost their turgidity, shriveled, and were covered by gray to black pycnidia. Pycnidia on the berry skin cause the cuticle to detach from the epidermis, resulting in white berries. At maturity, these pycnidia becomes greyish white. More than 20 partially desiccated diseased clusters were observed during the survey. In most of these clusters, more than half of the berries have been mummified. Infected rachises and pedicels initially appear as brown pin-point spots, which later become pale brown with elongated depressions. These symptoms were observed on all the diseased vines. Under high relative humidity, these infections spread from pedicels into uninjured berries. Within few days, whole clusters become desiccated. Cankers were observed on nonlignified shoots. The infections on green shoots often localized around the nodes. These colonized tissues become necrotic, exhibiting elongated, brownish, depressed areas. Irregular lesions with brown centers were observed on the leaf blades near the injured areas, which became lighter toward the diffused edges. In all of the diseased vines, leaf symptoms were visible clearly (Fig. 5).

Morphological characterization. Isolates of the newly identified Coniella species had identical sequences and produced pycnidial conidiomata in culture that contained narrowly ellipsoidal, hyaline conidia. All the isolates demonstrated identical cultural characteristics. Colonies on PDA medium had crenulated edges with concentric rings and were fast growing up to $8 \mathrm{~cm}$ in diameter after 5 days of incubation at $28^{\circ} \mathrm{C}$. Mycelia were mostly immersed, and were rarely visible due to sparse aerial mycelia. The upper surface of colonies was mostly flat and white with many pycnidia, and the bottom surface was buff (Fig. 4). Conidial masses secreted from conidiomata were white. The following taxonomic description provides the detailed morphological characters of this new Coniella species.

Taxonomic description. Coniella vitis Chethana, Yan, Li \& K.D. Hyde, sp. nov. Fig. 4. MycoBank no. MB 819365. Faces Of Fungi no. FoF 02722.

The newly identified species is pathogenic on berries of Vitis vinifera. Asexual morph is coelomycetous. Conidiomata were 150 to $260 \mu \mathrm{m}(\overline{\mathrm{x}}=203 \mu \mathrm{m}, \mathrm{n}=20)$ in diameter, pycnidial, solitary, submerged in PDA, globose to slightly depressed globose, with verruculose wall, initially hyaline and turned dark brown to black at maturity, with a central ostiole. Conidiophores were 5 to $8 \times 1$ to $3 \mu \mathrm{m}(\overline{\mathrm{x}}=$ $6.8 \times 2.3 \mu \mathrm{m}, \mathrm{n}=10$ ), formed on a dense, cushion-like aggregation of hyaline cells, subcylindrical, hyaline, smooth, simple or branched below, mostly reduced to conidiogenous cells. Conidiogenous cells were 8 to $13 \times 1$ to $3 \mu \mathrm{m}(\overline{\mathrm{x}}=10.7 \times 2.5 \mu \mathrm{m}, \mathrm{n}=10)$, hyaline, simple, slender, smooth with a prominent periclinal thickening. Conidia were 7.9 to $12.8 \times 3.3$ to $6.5 \mu \mathrm{m}(\overline{\mathrm{x}}=10.41 \times 5.07 \mu \mathrm{m}, \mathrm{n}=40)$, length: width ratio 2.0 , inequilateral, hyaline when immature becoming pale brown, aseptate, straight to slightly curved, narrowly ellipsoidal, often somewhat flattened on one side, both sides gradually tapering towards the subobtusely rounded apex, subtruncate base, smooth-walled, and multi-guttulate with one or two prominent guttules. Sexual morph is undetermined.

Etymology. Named after the host genus on which it occurs, Vitis.

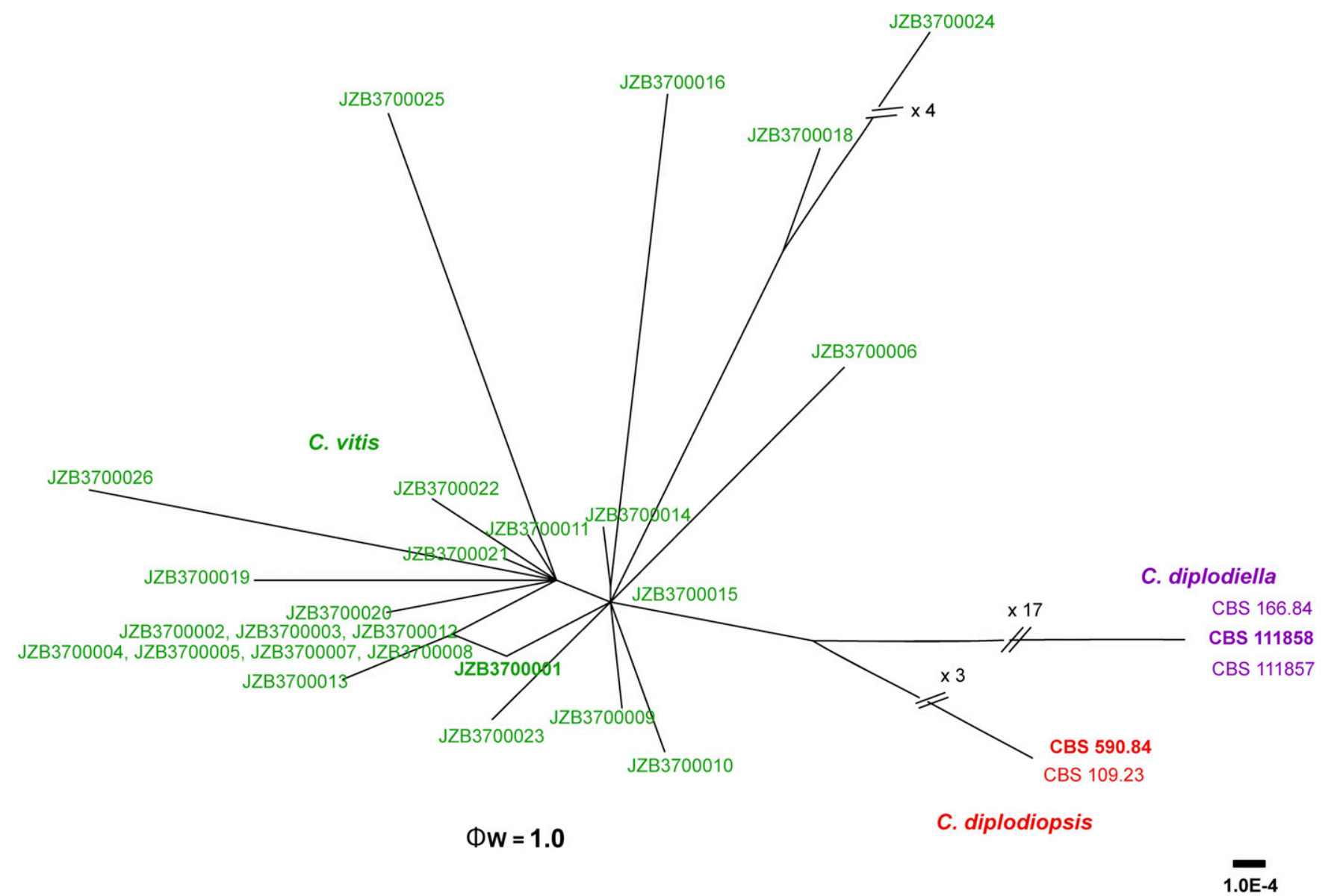

Fig. 3. The results of the pairwise homoplasy index (PHI) test for closely related species of Coniella vitis using both LogDet transformation and splits decomposition. PHI test results $(\Phi w)<0.05$ indicate significant recombination within the dataset. 
Material examined. CHINA. Yanqing, Beijing, on white rotinfected berries of Vitis vinifera (Vitaceae), 13 May 2015, XingHong Li JZB3700001 (MFLU 16-2677, holotype, dried sporulating culture on PDA), ex-type living culture, MFLUCC 16-1399; Isotype JZB3700019 (HKAS96352, dried sporulating culture on PDA), extype living culture, MFLUCC 16-1400).

Additional material examined. Paratypes CHINA. Guangxi province, leaf symptoms of $V$. vinifera, 3 May 2015, XingHong Li, JZB3700012 (living culture, MFLUCC 16-1401); CHINA. Henan province, on infected shoots of $V$. vinifera, 5 May 2014, XingHong Li, JZB3700002 (living culture, MFLUCC 16-1402); CHINA. JiLin province, infected shoot of $V$. vinifera, 3 May 2015, XingHong Li, JZB3700014 (living culture, MFLUCC 16-1403); CHINA. Hebei province, infected berry of $V$. vinifera, 3 May 2015, XingHong Li, JZB3700016 (living culture, MFLUCC 16-1404); CHINA. Yanqing, Beijing, rachis of an infected berry cluster of $V$. vinifera, 3 May 2015, XingHong Li, JZB3700021 (living culture, MFLUCC 161405).

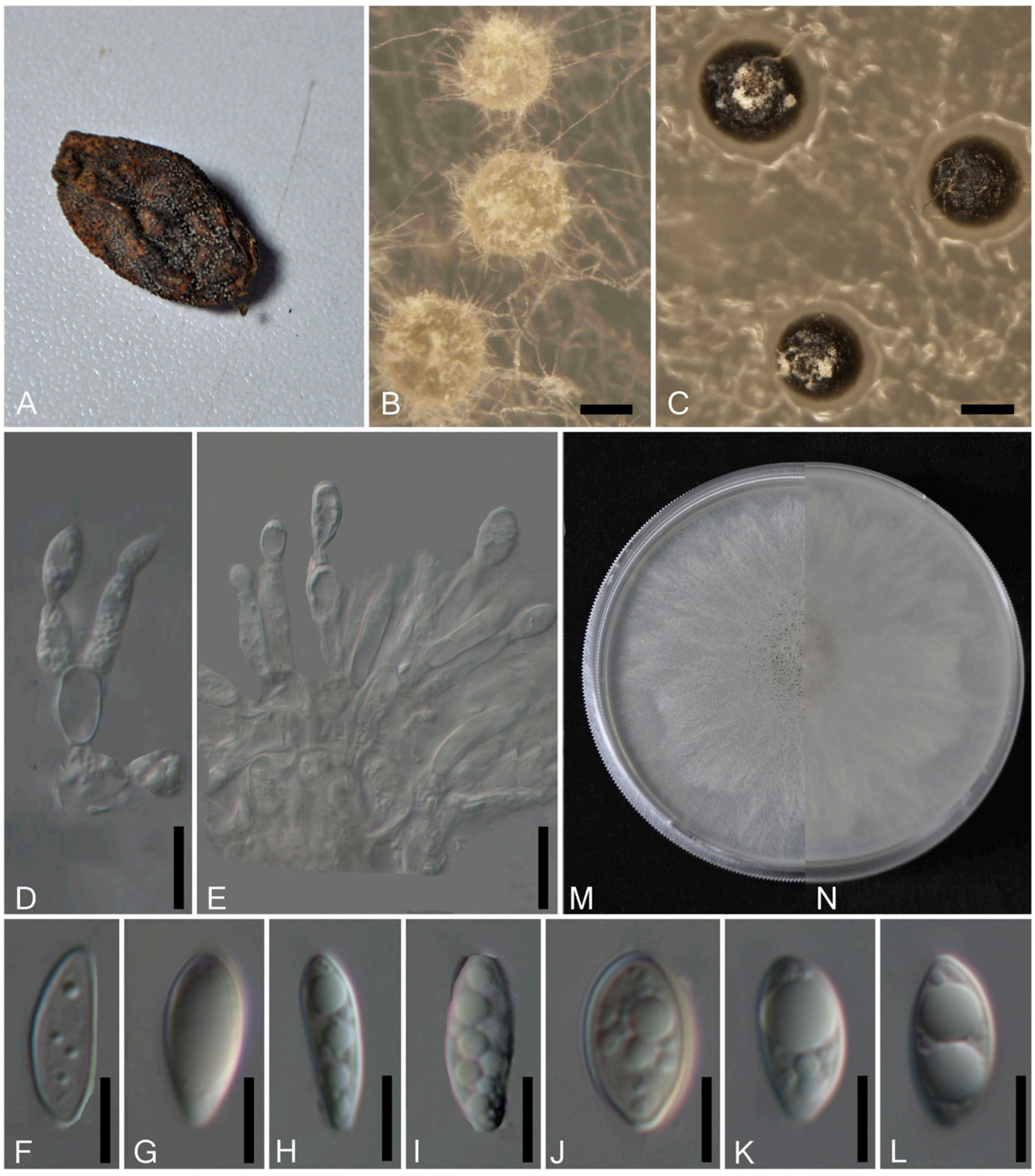

Fig. 4. Morphological characteristics of Coniella vitis (JZB3700001). A, Black pycnidia on heavily infected host tissue. B, Immature white pycnidia on the PDA. C, Mature pycnidia with whitish spore mass. D, Conidiogenous cells. E, Periclinal thickening at the apex of the conidiogenous cells. F to L, Different shapes of conidia. M, Upper view showing pycnidia on the PDA and, N, the reverse view of the colony on PDA. Scale bars: B, C, $100 \mu \mathrm{m} ; \mathrm{D}, \mathbf{E}, 10 \mu \mathrm{m} ; \mathbf{F}$ to L, $5 \mu \mathrm{m}$. 
Pathogenicity test. Detached leaf inoculation. Lesions similar to those observed in the field were recorded on leaves after three days. Irregular necrotic lesions formed on the wounded leaves on the third day. After five days, these lesions expanded and the wounded areas became covered with brown to black pycnidia, which turned to graywhite at maturity after a week. No symptoms were observed on nonwounded inoculated leaves or on wounded and nonwounded leaves maintained as controls. Reisolation from lesions and from the pycnidia confirmed the inoculated fungus based on cultural and morphological characters such as white colonies with sparse, crenulated edges and concentric rings; and hyaline, inequilateral, straight to slightly curved and narrowly ellipsoidal conidia with a length:width ratio of 2.0. All four replicates yielded the same results (Fig. 6). Different isolates of $C$. vitis recorded in this study showed significantly different virulence on grape leaves $\left(\mathrm{F}_{5}=68.86, P=0.000\right)$ as shown in Figure 6I. Among all isolates, JZB3700012, isolated from symptomatic leaves from Guangxi province, was the most virulent.

Detached fruit inoculation. The fruit inoculation assay was performed at three berry stages (Fig. 7 and 8). Among the three stages, clusters at the formation stage with pea sized berries were easily infected. This stage was the first to exhibit symptoms for all the isolates. Five days post inoculation, rachises of these clusters showed irregular necrotic lesions and pycnidia on the surface. However, clusters at other berry ripening stages did not show any symptoms. A week after the inoculation, black pycnidia appeared on these rachises and the infection spread to the berries (Fig. 7 and 8). Most of the berries in formation-stage clusters (pea-sized berries) turned from green to brown. In some isolates (JZB3700001 and JZB3700014), the berries and the rachises were completely covered with pycnidia at seven days post inoculation. Green and red berry clusters at their ripening stages lost their turgidity and started changing from green to pinkish. Few of the berries at these two stages were covered with pycnidia at seven days post inoculation. At two weeks post inoculation, all the pea-sized berry clusters were covered with pycnidia and on some berries pycnidia turned white (especially for JZB3700001 and JZB3700014). Water-soaked regions formed around the wound of wound-inoculated, red, young berries seven days after inoculation (Fig. 8). Subsequently, the skin around the water-soaked areas became discolored. White mycelia appeared on the water-soaked areas, and cracks appeared on the berry skin. Two weeks post inoculation, most of the berry surface was covered with light brown to black pycnidia, turgidity was lost, and some berries were shrunken. Berry clusters maintained as the control and the berry clusters with nonwound inoculation remained asymptomatic. The taxa reisolated from diseased fruits (from water-soaked tissues and mycelia and pycnidia that formed at the infection site) were identical to the original isolates. Identification of the reisolated fungus was confirmed based on cultural and morphological characters such as white colonies with sparse, crenulated edges and concentric rings, and hyaline, inequilateral, straight to slightly curved, and narrowly ellipsoidal conidia with a length:width ratio of 2.0. All four replicates yielded the same results, but the virulence was highest in JZB3700001. In addition, C. vitis isolates JZB3700006 and JZB3700014 also exhibited high levels of virulence compared with other isolates. These three isolates infected the clusters more rapidly compared with other isolates (Fig. 7 and 8).

Direct plant inoculation. Living plants exhibited typical white rot symptoms on shoots and on leaves. Five weeks post inoculation brown necrotic areas were formed on the shoots. On the infected shoots, leaves exhibited light brown lesions, and some turned completely brown. One month after the inoculation, most of the leaves turned completely light brown and the necrotic areas on the shoots collapsed into necrotic shoots. All the five plants showed the typical symptoms, whereas control plants did not show any type of symptom (Fig. 6).

\section{Discussion}

Grape white rot is found in viticulture regions with warm, humid summers in Africa, Asia, Australasia, Europe, North and South America, and Oceania (Cho and Shin 2004; Crous et al. 2000; Mathur 1979; Plantwise Knowledge Bank 2012; van Niekerk et al. 2004; Zhuang
2001). It has also been reported in China, a country with one of the most extensive grape cultivation areas in the world. According to surveys conducted on grape white rot disease in China during 2015 and 2016, severe incidence of the disease was found on the fruit in major grapevine-cultivating provinces. The disease has been previously reported from many Chinese vineyards as a minor disease. According to grape growers, the disease was minimized by proper agricultural practices including maintaining trellis structures as high as possible ( 70 to $80 \mathrm{~cm}$ ) above the soil to increase the height of the fruit and shoot position. In addition, shoot thinning, leaf removal, pruning, cluster thinning, and shoot positioning have also been conducted by growers to reduce humidity and increase air and light circulation in the vineyards. In 2016, most of the vine-growing provinces experienced extremely conducive environmental conditions including heavy rainfall, storms, and hailstorms. These conditions, especially hailstorms and heavy rainfall, facilitated the infections by creating wounds on berries, which contributed to the build up of inoculum. During the fruit formation period, berries and rachis were infected by the pathogen, leading to severe conditions during the fruit ripening stage. After these extremely conducive environmental conditions, we observed an increment on the incidence of white rot disease even in those areas where proper management agricultural practices were followed.

The white rot pathogen belongs to genus Coniella, a genus mainly composed of many pathogens and some secondary invaders of plant
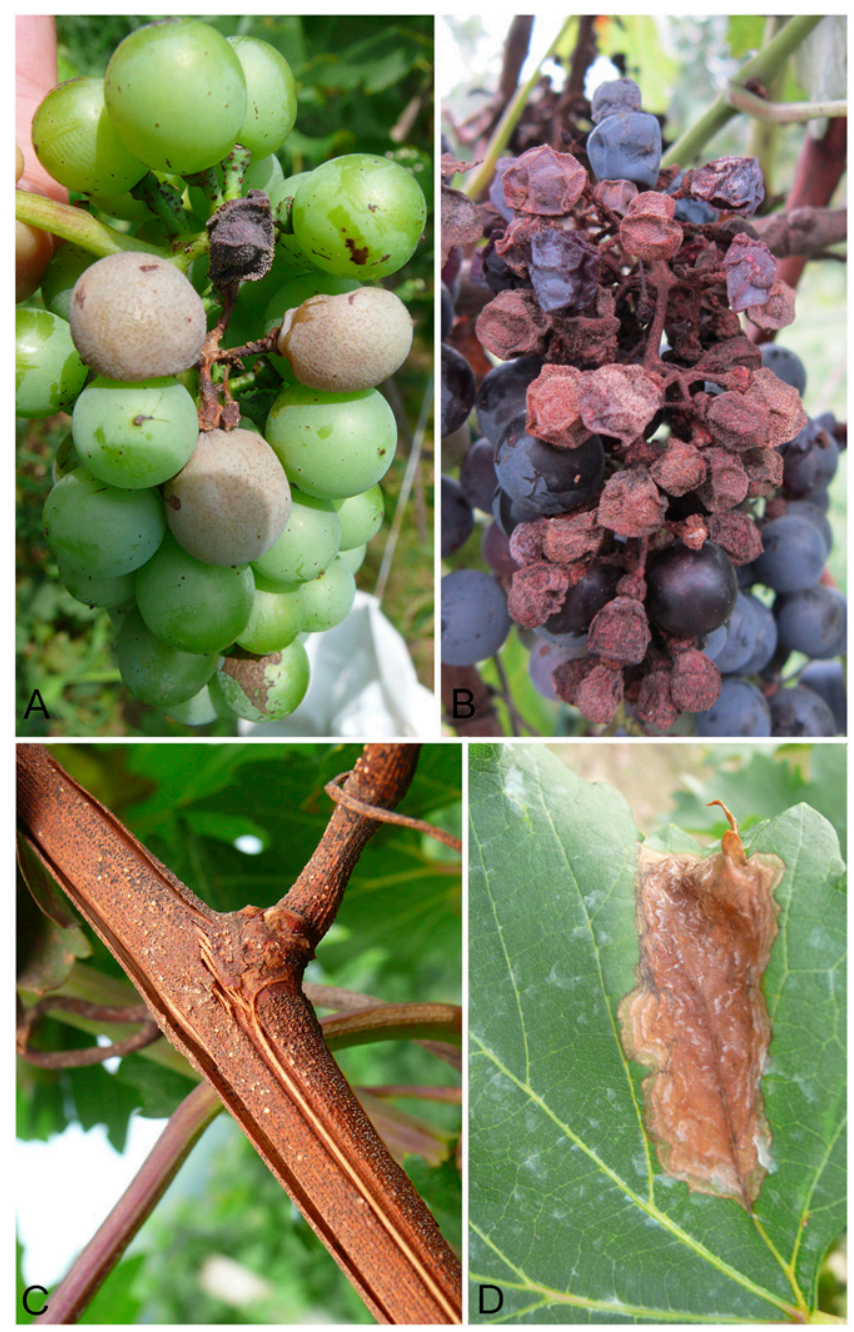

Fig. 5. Disease symptoms of grape white rot on Vitis vinifera cv. Summer Black in the field. A, Immature berries change color from pale green to brown. B, Shrunken berries covered with pycnidia, infected pedicels, and rachis leading to desiccation and death of clusters. C, Cracks on long depressed brownish, necrotic areas on shoots. D, Leaf symptoms: Irregular lesions with brown center and amphigenous gray-white pycnidia on brown lesions. 
tissues (Alvarez et al. 2016). Coniella, together with the asexual genus Pilidiella Petr. \& Syd., typified by P. quercicola (Oudem.) Petr., and Schizoparme Shear, typified by S. straminea Shear, belong to the family Schizoparmaceae Rossman, D.F. Farr \& Castl. (Maharachchikumbura et al. 2015, 2016; Rossman et al. 2007). Links between the genus Schizoparme and its asexual genera, Coniella and Pilidiella, were first recognized by Samuels et al. (1993), and several studies have confirmed this relationship (Alvarez et al. 2016; Miranda et al. 2012; Rossman et al. 2007). Initially, Coniella was positioned in Melanconidaceae, but later, Castlebury et al. (2002) showed their distinct lineage in Diaporthales and referred to them as the Schizoparme complex. Coniella and Pilidiella were treated as separate genera by van der Aa (von Arx 1973) and von Arx (1981), considering the pigmentations in their conidia. Nag Raj (1993) and Sutton (1980) rejected this theory and synonymized Pilidiella under Coniella, considering their identical fruiting bodies, conidiogenesis, and conidiophore orientations. Following Castlebury et al. (2002), many studies confirmed that Pilidiella is distinct from Coniella based on their phylogenetic analyses (van Niekerk et al. 2004; Wijayawardene et al. 2016). In accordance to one name for one fungus based on the International Code of Nomenclature for algae, fungi and plants (McNeill et al. 2012), Alvarez et al. (2016) synonymized Pilidiella and Schizoparme under their older name Coniella.

Here, we defined a novel species, Coniella vitis, by considering its morpho-cultural characteristics and its placement in the phylogenetic trees inferred from ITS, LSU, HIS, and TEF $1-\alpha$ gene regions. Single-gene and multigene analyses were conducted to delineate the pathogenic species of white rot with high resolution. Most of
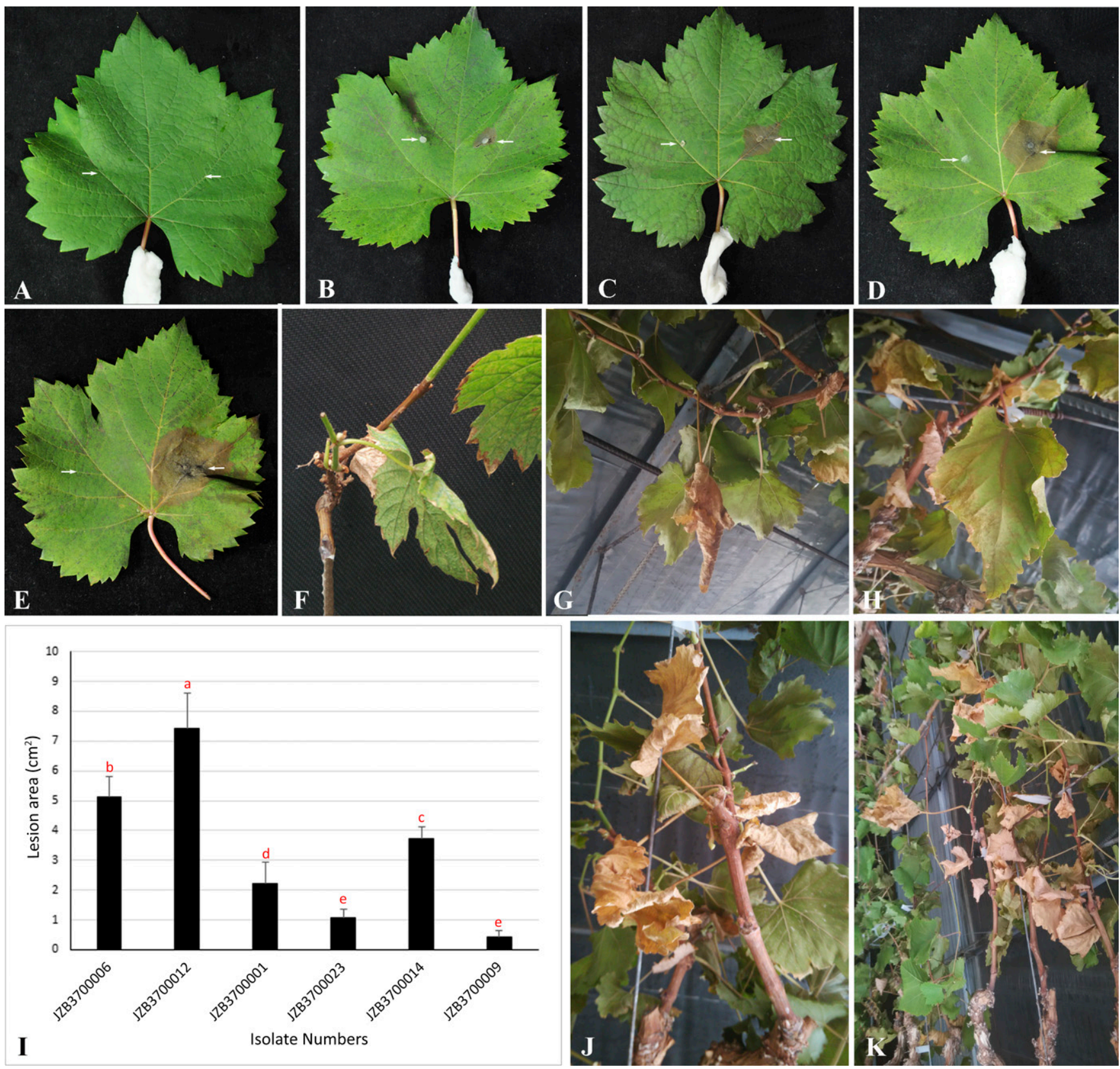

Fig. 6. Detached-leaf pathogenicity assay and whole-plant inoculation results of Coniella vitis (JZB3700001) on V. vinifera cv. Summer Black. A to E, Symptoms on leaves inoculated with mycelial plugs of $C$. vitis: right, wound inoculation; left, nonwound inoculation. A, Grape leaves inoculated with PDA plug (control). B, C, D, Necrotic areas of leaves three days post inoculation by JZB3700001, JZB3700006, and JZB3700012 strains, respectively. E, Necrotic areas and pycnidia five days post inoculation by JZB3700012. F to H, J, K, Symptoms resulted from whole-plant inoculation on shoots and leaves of infected plants. I, Variations in the virulence of lesion area of Coniella vitis isolates on grape leaves resulted from the pathogenicity test three days post inoculation. JZB3700012 showed the highest virulence of all isolates. Red characters indicate the significant differences for lesion area. Isolates that do not share same letter are significantly different. 

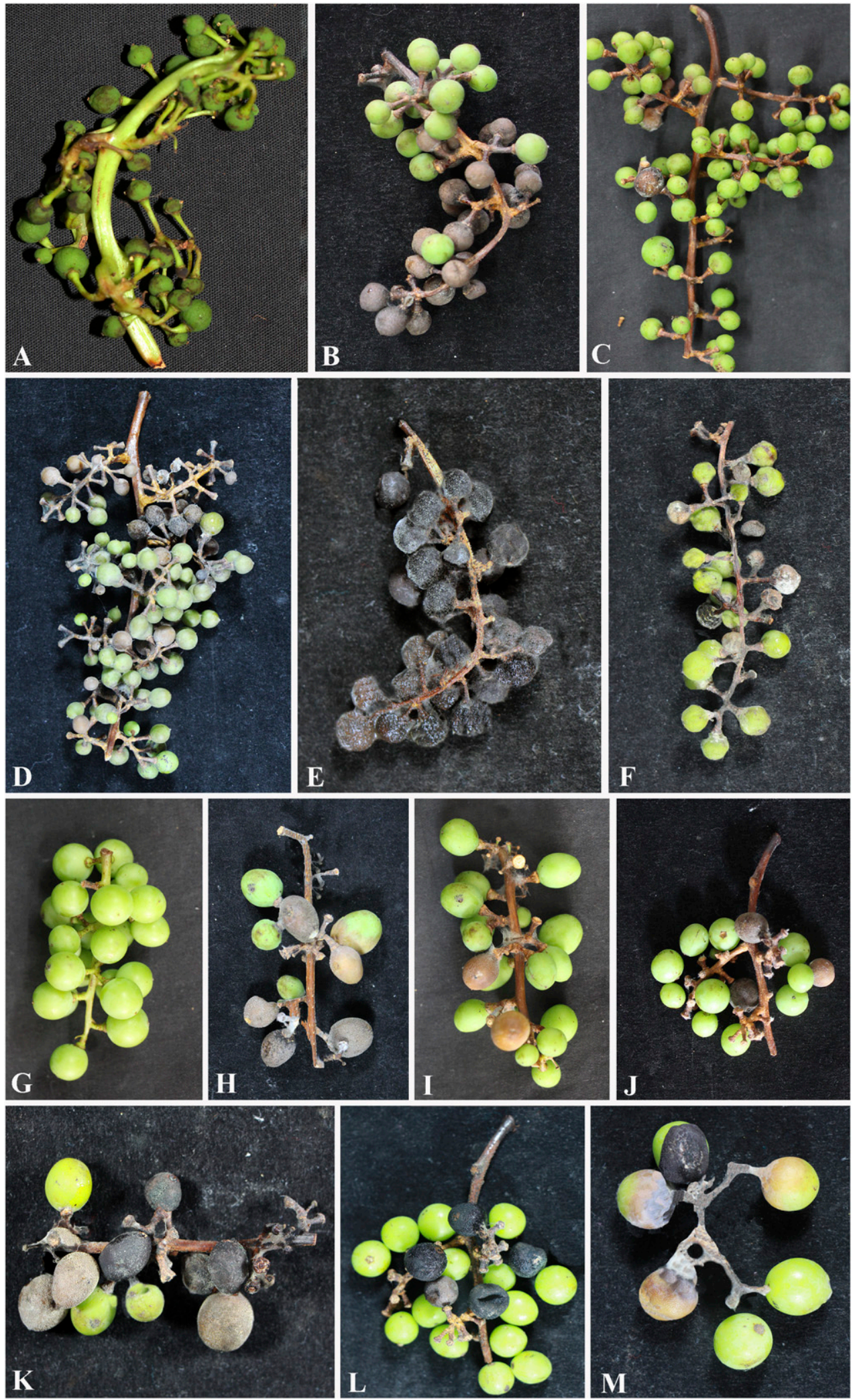

Fig. 7. Detached fruit inoculation assays on V. vinifera cv. Summer Black berry clusters. Control treatment with sterile water on, A, pea-sized berries and, G, young hard, green berries at the ripening stage. B to D, Symptoms on pea-sized berry clusters seven days after wound inoculation by $\mathbf{C}$. vitis. B, Pycnidia were visible on most of the berries and rachises infected by highly virulent $C$. vitis isolate JZB3700001. Compared with C. vitis isolate JZB3700001, clusters inoculated by C, JZB3700014 and D, JZB3700006 showed less infection with only few berries and rachises covered pycnidia. E, F, Symptoms on pea-sized berry clusters 14 days after wound inoculation by C. vitis isolates JZB3700001 and JZB3700014. E, Fourteen days post inoculation, cluster infected by isolate JZB3700001 completely desiccated with pycnidia on berries and rachis, and the disease spread into berries in cluster infected by JZB3700006 with pycnidia on berries and rachis. $\mathrm{H}$ to J, Symptoms on young, hard, green berry clusters seven days after wound inoculation by $\mathrm{C}$. vitis isolates JZB3700001, JZB3700014, and JZB3700006 respectively. Few berries showed pycnidia on the berry surface, and only the clusters infected by, H, JZB3700001 and, J, JZB3700006 showed pycnidia on the rachis. K to M, Symptoms on young, hard, green berry clusters 14 days after wound inoculation by C. vitis isolates JZB3700001, JZB3700006, and JZB3700014, respectively. Almost all the berries and rachis were covered with pycnidia in the cluster infected by, K, isolate JZB3700001. Only a few of the berries were completely covered with pycnidia, while the other berries has changed color in clusters infected by, L, isolates JZB3700006 and, M, JZB3700014. In these clusters rachises were completely infected with visible pycnidia on the surface. 
the previous phylogenetic studies conducted on Coniella species were based on single-gene phylogeny (Castlebury et al. 2002; Miranda et al. 2012; van Niekerk et al. 2004), except for Alvarez et al. (2016). Castlebury et al. (2002) and Miranda et al. (2012) used LSU and ITS phylogeny separately to identify the species in these taxa. In the study conducted by Alvarez et al. (2016), multigene phylogeny (ITS, LSU, RPB2, and TEF 1- $\alpha$ ) was successfully used to resolve species within the genus. However, some Coniella species were not included in their multigene phylogenetic analyses $(C$. crousii, Coniella eucalyptigena (Crous \& M.J. Winf.) L.V. Alvarez \& Crous, Coniella musaiaensis B. Sutton, and Coniella pseudogranati (Crous) L.V. Alvarez \& Crous). Similar to our study, van Niekerk et al. (2004) performed single-gene (ITS, LSU, histone, and TEF
1- $\alpha$ genes) phylogenetic analyses. Each of these gene regions addressed different aspects during the phylogenetic analyses, and they were combined using a partition homogeneity test. Therefore, in our study, we combined the gene regions, which provided the best topology compared with the single gene topologies. The combined analysis in our study allowed all of these aspects to be combined in one tree rather than having to generate several trees to represent each aspect. In addition, GCPSR analyses also confirmed $C$. vitis as a new species.

The multigene phylogenetic analyses showed 25 isolates belonging to $C$. vitis but with various genotypes. Coniella vitis isolates exhibited high phylogenetic divergence. According to the phylogenetic analyses, all of the isolates belonging to $C$. vitis formed a clade
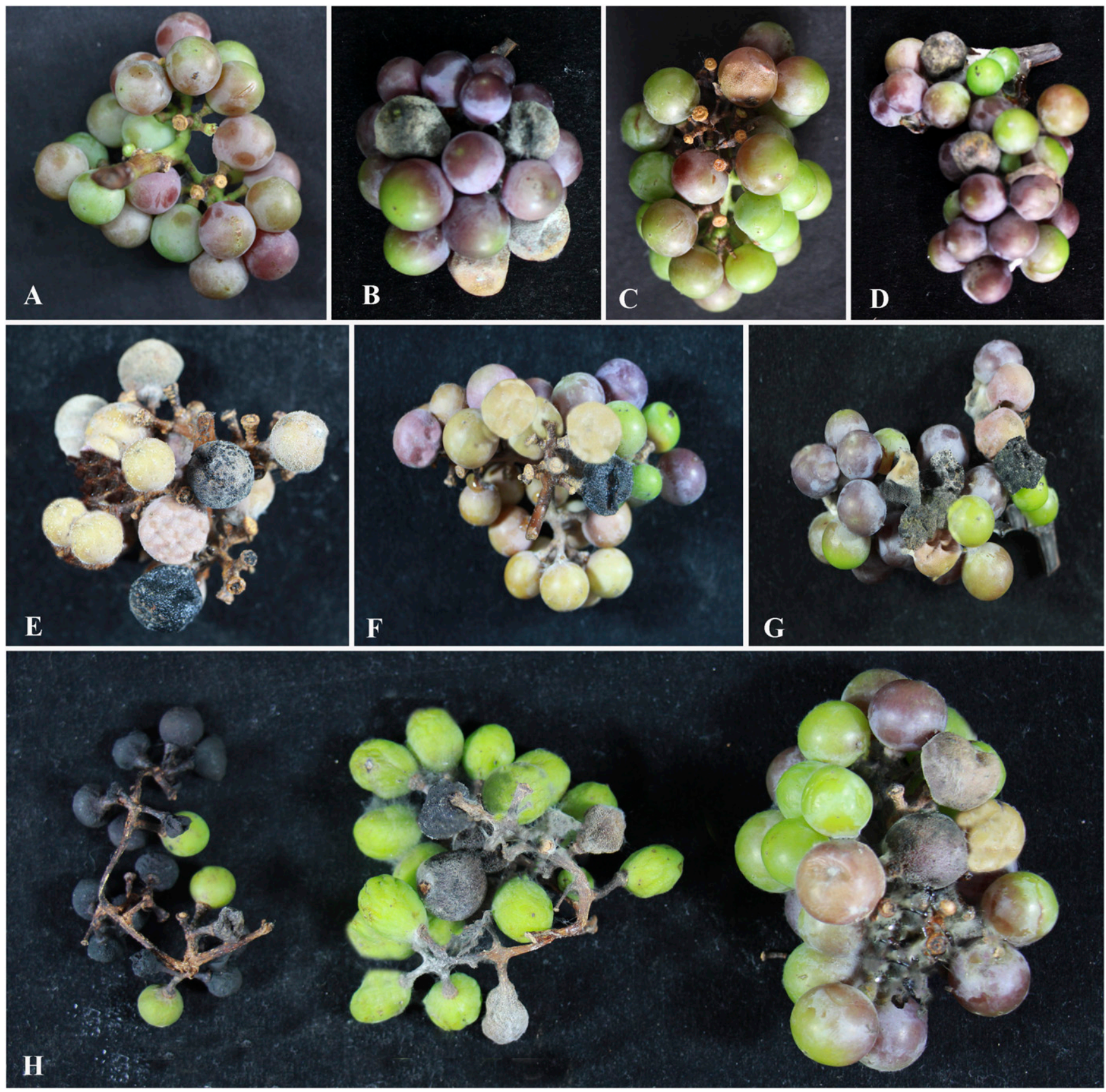

Fig. 8. Detached fruit inoculation assays on V. vinifera cv. Summer Black berry clusters with young, hard, red berries. A, Control treatment with sterile water on young, red berries. B to D, Symptoms on young, red berry clusters seven days after wound inoculation by C. vitis isolates JZB3700001, JZB3700014, and JZB3700006 respectively. Only a few berries were covered with black pycnidia and water-soaked lesions were seen on few berries. $E$ to $\mathbf{G}$, Symptoms on young, red berry clusters 14 days after wound inoculation by $C$. vitis isolates E, JZB3700001, G, JZB3700014, and F, JZB3700006. Infections spread through rachis and berries; many berries and all the rachises were covered with black pycnidia. H, Susceptibility to infection by $C$. vitis on three different stages of berry clusters seven days post inoculation. Among the three stages, clusters at the formation stage with pea-sized berries were easily infected. 
that was well separated from $C$. diplodiopsis. Morphologically, C. vitis is similar to $C$. diplodiella and $C$. diplodiopsis but differs from $C$. diplodiopsis (length:width ratio 1.7 ) by having longer conidia with subobtusely rounded apices and a higher length:width ratio (2.0) (van Niekerk et al. 2004). They differ from $C$. diplodiella (length:width 2.3) by having smaller conidiophores and a lower length:width ratio (2.0) (van Niekerk et al. 2004). In accordance with the phylogenetic divergence, pathogenicity assays also demonstrated a high level of variability among the $C$. vitis isolates. Virulence toward the Summer Black cultivar differed significantly among the isolates. According to the pathogenicity results, berries exhibited high susceptibility to infection during fruit formation compared with the initial period of fruit formation. Especially during the fruit formation stage with pea-sized berries, $C$. vitis infections spread easily. Considering all of the molecular, morphological, and pathogenicity data, C. vitis is introduced as a new pathogenic species causing grape white rot in China. Coniella vitis exhibited certain divergence in the phylogenetic analyses as well as in the pathogenicity assays. However, according to the GCPSR analysis, it was confirmed that all of our $C$. vitis isolates belong to the same species. Hence, we suggest $C$. vitis as a species with a cryptic lineage.

To our knowledge, this is the first study that has identified and characterized the grape white rot pathogen in China by both morphological and molecular techniques. Pathogenicity tests also confirmed $C$. vitis as another causal agent of grape white rot in China. Identification of this new pathogen is important for disease management, which is based on identifying the disease symptoms at initial stage and taking actions during weak stages in the disease cycle. These management practices were based on the knowledge of a specific disease, life cycles of the pathogen, time and the method of infection, affected plant parts, pathogen distribution methods, and other agronomic and economic considerations (Mahmood and Kerr 2001). Even though early detection and monitoring are important for any disease management program, the most critical step is the accurate identification of the pathogen. Correct identification of the pathogen, $C$. vitis, becomes an important issue in the management of grape white rot, especially when pathogenicity varies with the species within a genus. Since there are many Coniella species isolated from grapevines that do not exhibit any pathogenicity, identification of $C$. vitis and its virulence will allow the improvement of management strategies.

In previous studies, $C$. diplodiella was the only causal agent of grape white rot in Chinese vineyards (Bisiach 1988; Cortesi 2015; Crous and Carstens 2000; Crous et al. 2000; van Niekerk et al. 2004). However, now a new pathogen, $C$. vitis, has been identified from China. The identification of $C$. vitis as a new pathotype in the field may illustrate the possibility of pathogenic taxa evolving in response to several environmental and human factors. The new pathogen evolved in the current context under the existing chemical control methods, and thus if the traditional fungicides used to control $C$. diplodiella are applied, there is a possibility that it would not work against $C$. vitis. Therefore, studies must be conducted to ensure the efficacy of traditional protective fungicides such as pthalimides, dichlofluanid, and chlorothalonil (Cortesi 2015) against the white rot caused by $C$. vitis. Representative isolates used in the current study for pathogenicity tests (JZB3700001, JZB3700006, JZB3700009, JZB3700012, and JZB3700014) can be utilized for screening high efficiency fungicides against grape white rot. However, proper agricultural practices such as maintaining trellis structures as high as possible will prevent creating wounds on berries. Since these wounds act as main entry points for $C$. vitis, preventing them will prevent its infection. High humidity conditions along with warm temperatures facilitate the spread of infections by favoring the growth of this pathogen. Therefore, cultural practices such as leaf removal, pruning, cluster thinning, and shoot positioning will help to reduce humidity and increase air circulation among the vines, thereby creating unfavorable conditions for $C$. vitis. Since most of $V$. vinifera cultivars are highly susceptible to white rot ( $\mathrm{Li}$ et al. 2008a), planting resistant cultivars is important in preventing the disease. Li et al. (2008a) classified several Chinese wild Vitis species including $V$. amurensis, $V$. piazekii, $V$. davidii var. cyanocarpa, V. liubanensis, V. qinlingensis, V. bashanica, V. yeshanensis, and V. hankockii as resistant to grape white rot. In order to overcome the pathogen adaptation and evolution against the management practices, disease management approaches need diversification. For this, further understanding on the impact and the epidemiology of grape white rot in China is necessary. In the current study, we only investigated several main grapegrowing provinces. In future studies, disease-sample collection area should be further expanded to all the provinces in China. If possible, Coniella diplodiella cultures previously identified in China based only on morphological characters should be reinvestigated. In the current study, we have exhibited the variations in the pathogenicity of this grape white-rot pathogen. Research can now focus on species population dynamics and disease epidemiology to design more effective disease management strategies against this pathogen.

\section{Acknowledgments}

The project was funded by CARS-30, D17110500160000, and JNKYT201605. We would like to thank grape cultivators for providing disease samples, R. S Jayawardena, A. J. Dissanayake, and L. Mei for providing isolates for the study K. D. Hyde thanks Kunming Institute of Botany, Chinese Academy of Sciences (project 2013T2S0030) for the Visiting Professorship for Senior International Scientists.

\section{Literature Cited}

Alvarez, L. V., Groenewald, J. Z., and Crous, P. W. 2016. Revising the Schizoparmaceae: Coniella and its synonyms Pilidiella and Schizoparme. Stud. Mycol. 85:1-34.

Bisiach, M. 1988. White rot. Pages 22-23 in: Compendium of Grape Diseases R. C. Pearson and A. C. Gohen, eds. American Phytopathological Society, St. Paul, MN.

Carbone, I., and Kohn, L. M. 1999. A method for designing primer sets for speciation studies in filamentous ascomycetes. Mycologia 91:553-556.

Castlebury, L. A., Rossman, A. Y., Jaklitsch, W. J., and Vasilyeva, L. N. 2002. A preliminary overview of the Diaporthales based on large subunit nuclear ribosomal DNA sequences. Mycologia 94:1017-1031.

Changyaun, L., Kuihua, Z., Ke, W., and Jinkai, B. 1999. Redesignation of the causal agent of grape white rot in China. Acta Phytopathol. Sin. 29:174-176.

Cho, W. D., and Shin, H. D., eds. 2004. List of Plant Diseases in Korea, 4th Ed Korean Society of Plant Pathology, Suwon, South Korea.

Chomnunti, P., Hongsanan, S., Aguirre-Hudson, B., Tian, Q., Peršoh, D., Dhami, M. K., Alias, A. S., Xu, J. C., Liu, X. Z., Stadler, M., and Hyde, K. D. 2014. The sooty moulds. Fungal Divers. 66:1-36.

Cortesi, P. 2015. White rot. Pages 92-94 in: W. F. Wilcox, W. D. Gubler, and J. K. Uyemoto, 2015. Compendium of Grape Diseases, Disorders and Pests. American Phytopathological Society, St. Paul, MN.

Crous, P. W., and Carstens, E. 2000. Confusion surrounding white rot disease of grapevines. Winelands 9:89-90.

Crous, P. W., Phillips, A. J. L., and Baxter, A. P. 2000. Phytopathogenic Fungi from South Africa. Univ. of Stellenbosch, Dept. of Plant Pathol., Stellenbosch, South Africa.

Crous, P. W., Shivas, R. G., Quaedvlieg, W., van der Bank, M., Zhang, Y., Summerell, B. A., Guarro, J., Wingfield, M. J., Wood, A. R., Alfenas, A. C., Braun, U., Cano-Lira, J. F., García, D., Marin-Felix, Y., Alvarado, P., Andrade, J. P., Armengol, J., Assefa, A., den Breeÿen, A., Camele, I., Cheewangkoon, R., De Souza, J. T., Duong, T. A., Esteve-Raventós, F., Fournier, J., Frisullo, S., García-Jiménez, T., Gardiennet, A., Gené, J., Hernández-Restrepo, M., Hirooka, Y., Hospenthal, D. R., King, A., Lechat, C., Lombard, L., Mang, S. M., Marbach, P. A. S., Marincowitz, S., MarinFelix, Y., Montaño-Mata, N. J., Moreno, G., Perez, C. A., Pérez Sierra, A. M., Robertson, J. L., Roux, J., Rubio, E., Schumacher, R. K., Stchigel, A. M., Sutton, D. A., Tan, Y. P., Thompson, E. H., van der Linde, E., Walker, A. K., Walker, D. M., Wickes, B. L., Wong, P. T. W., and Groenewald, J. Z. 2014. Fungal Planet description sheets: 214-280. Persoonia 32:184-306.

Crous, P. W., Slippers, B., Wingfield, M. J., Rheeder, J., Marasas, W. F. O., Phillips, A. J. L., Alves, A., Burgess, T. I., Barber, P. A., and Groenewald, J. Z. 2006. Phylogenetic lineages in the Botryosphaeriaceae. Stud. Mycol. 55:235-253.

Crous, P. W., Summerell, B. A., Shivas, R. G., Burgess, T. I., Decock, C. A., Dreyer, L. L., Granke, L. L., Guest, D. I., Hardy, G. E. St. J., Hausbeck, M. K., Hüberli, D., Jung, T., Koukol, O., Lennox, C. L., Liew, E. C. Y., Lombard, L., McTaggart, A. R., Pryke, J. S., Roets, F., Saude, C., Shuttleworth, L. A., Stukely, M. J. C., Vánky, K., Webster, B. J., Windstam, S. T., and Groenewald, J. Z. 2012. Fungal Planet description sheets: 107-127. Persoonia 28:138-182

Crous, P. W., Wingfield, M. J., Guarro, J., Hernández-Restrepo, M., Sutton, D. A., Acharya, K., Barber, P. A., Boekhout, T., Dimitrov, R. A., Dueñas, M., Dutta, A. K., Gené, J., Gouliamova, D. E., Groenewald, M., Lombard, L., Morozova, O. V., Sarkar, J., Smith, M. Th., Stchigel, A. M., Wiederhold, N. P., Alexandrova, A. V., Antelmi, I., Armengol, J., Barnes, I., Cano-Lira, J. F., Castañeda Ruiz, R. F., Contu, M., Courtecuisse, Pr. R., da Silveira, A. L., Decock, C. A., Goes, A. de., Edathodu, J., Ercole, E., Firmino, A. C., Fourie, 
A., Fournier, J., Furtado, E. L., Geering, A. D. W., Gershenzon, J., Giraldo, A., Gramaje, D., Hammerbacher, A., He, X. -L., Haryadi, D., Khemmuk, W., Kovalenko, A. E., Krawczynski, R., Laich, F., Lechat, C., Lopes, U. P., Madrid, H., Malysheva, E. F., Marin-Felix, Y., Martín, M. P., Mostert, L., Nigro, F., Pereira, O. L., Picillo, B., Pinho, D. B., Popov, E. S., Rodas Peláez, C. A., Rooney-Latham, S., Sandoval-Denis, M., Shivas, R. G., Silva, V., Stoilova-Disheva, M. M., Telleria, M. T., Ullah, C., Unsicker, U. B., van der Merwe, N. A., Vizzini, A., Wagner, H.-G., Wong, P. T. W., Wood, A. R., and Groenewald, J. Z. 2015. Fungal Planet description sheets: 320370. Persoonia 34:167-266.

Glass, N. L., and Donaldson, G. C. 1995. Development of primer sets designed for use with the PCR to amplify conserved genes from filamentous ascomycetes. Appl. Environ. Microbiol. 61:1323-1330.

Guo, L. D., Hyde, K. D., and Liew, E. C. Y. 2000. Identification of endophytic fungi from Livistona chinensis (Palmae) using morphological and molecular techniques. New Phytol. 147:617-630.

Hall, T. A. 1999. BioEdit: A user-friendly biological sequence alignment editor and analysis program for Windows 95/98/NT. Nucleic Acids Symp. Ser. 41:95-98.

He, P. C. 1999. Viticulture. China Agriculture Press, Beijing, China.

Hillis, D. M., and Bull, J. J. 1993. An empirical test of bootstrapping as a method for assessing confidence in phylogenetic analysis. Syst. Biol. 42:182.

Hu, Y., Xing, C. Y., and Li, Y. J. 2010. Occurrence and control of grape white rot disease in Zhengzhou, Henan Province countermeasure. China Fruits 6:55-57.

Huson, D. H. 1998. SplitsTree: analyzing and visualizing evolutionary data. Bioinformatics 14:68-73.

Huson, D. H., and Bryant, D. 2006. Application of phylogenetic networks in evolutionary studies. Mol. Biol. Evol. 23:254-267.

Jayasiri, S. C., Hyde, K. D., Ariyawansa, H. A., Bhat, D. J., Buyck, B., Cai, L., Dai, Y. C., Abd-Elsalam, K. A., Ertz, D., Hidayat, I., Jeewon, R., Jones, E. B. G., Bahkali, A. H., Karunarathna, S. C., Liu, J. K., Luangsa-ard, J. J., Lumbsch, H. T., Maharachchikumbura, S. S. N., McKenzie, E. H. C., Moncalvo, J. M., Ghobad-Nejhad, M., Nilsson, H., Pang, K. L., Pereira, O. L., Phillips, A. J. L., Raspé, O., Rollins, A. W., Romero, A. I., Etayo, J., Selçuk, F., Stephenson, S. L., Suetrong, S., Taylor, J. E., Tsui, C. K. M., Vizzini, A., Abdel-Wahab, M. A., Wen, T. C., Boonmee, S., Dai, D. Q., Daranagama, D. A., Dissanayake, A. J., Ekanayaka, A. H., Fryar, S. C., Hongsanan, S., Jayawardena, R. S., Li, W. J., Perera, R. H., Phookamsak, R., de Silva, N. I., Thambugala, K. M., Tian, Q., Wijayawardene, N. N., Zhao, R. L., Zhao, Q., Kang, J. C., and Promputtha, I. 2015. The Faces of Fungi database: Fungal names linked with morphology, phylogeny and human impacts. Fungal Divers. 74:3-18.

Katoh, K., and Toh, H. 2008. Recent developments in the MAFFT multiple sequence alignment program. Brief. Bioinform. 9:286-298.

Kishino, H., and Hasegawa, M. 1989. Evaluation of the maximum likelihood estimate of the evolutionary tree topologies from DNA sequence data. J. Mol. Evol. 29:170-179.

Li, B. Z. 2012. Integrated control of grape white rot. Fujian Agr. 18:17.

Li, D., Wan, Y., Wang, Y., and He, P. 2008a. Relatedness of resistance to anthracnose and to white rot in Chinese wild grapes. Vitis 47:213-215.

Li, S. C., Zhi, Q. K., Li, J. C., Zhao, H. Y., and Wang, Z. J. 2008b. Integrated control of grape white rot. Hebei For. 4:33-34.

Liu, Z. H. 2003. Grape white rot. New Agr. 10: 36-37.

Magarey, R. D., Coffey, B. E., and Emmett, R. W. 1993. Anthracnose of grapevines, a review. Plann. P. Q. Aust. 8:106-110.

Maharachchikumbura, S. N., Hyde, K. D., Jones, E. B. G., McKenzie, E. H. C., Bhat, J. D., Dayarathne, M. C., Huang, S. K., Norphanphoun, C., Senanayake, I. C., Perera, R. H., Shang, Q. J., Xiao, Y., D'souza, M. J., Hongsanan, S., Jayawardena, R. S., Daranagama, D. A., Konta, S., Goonasekara, I. D., Zhuang, W. Y., Jeewon, R., Phillips, A. J. L., AbdelWahab, M. A., Al-Sadi, A. M., Bahkali, A. H., Boonmee, S., Boonyuen, N., Cheewangkoon, R., Dissanayake, A. J., Kang, J., Li, Q. R., Liu, J. K., Liu, X. Z., Liu, Z. Y., Luangsa-ard, J. J., Pang, K. L., Phookamsak, R., Promputtha, I., Suetrong, S., Stadler, M., Wen, T., and Wijayawardene, N. N. 2016. Families of Sordariomycetes. Fungal Divers. 79:1-317.

Maharachchikumbura, S. S. N., Hyde, K. D., Jones, E. B. G., McKenzie, E. H. C., Huang, S.-K., Abdel-Wahab, M. A., Daranagama, D. A., Dayarathne, M., D'souza, M., Goonadekara, I. D., Hongsanan, S., Jayawardena, R. S., Kirk, P., Konta, S., Liu, J.-K., Norphanphoun, C., Pang, K. L., Perera, R. H., Senanayake, I. C., Shang, Q., Shenoy, D., Xiao, Y., and Xu, J. 2015. Towards a natural classification and backbone tree for Sordariomycetes. Fungal Divers. 72:199-301.

Mahmood, T., and Kerr, E. D. 2001. Disease management. High Plains Integrated Pest Management. BugwoodWiki, Center for Invasive Species and Ecosystem Health, Univ. of Georgia, Tifton. Retrieved 29 September 2015, from https:// wiki.bugwood.org/Disease_Management

Mathur, R. S. 1979. The Coelomycetes of India. Bishen Singh Mahendra Pal Singh, Delhi, India.
Matthee, F. N., and Thomas, A. C. 1981. Rot Blanc in Vines: a new disease in South Africa. Decid. Fruit. Grow. 31:268-273.

McNeill, J., Barrie, F. R., Buck, W. R., and Turland, N., eds. 2012. International Code of Nomenclature for Algae, Fungi, and Plants (Melbourne Code) Regnum Vegetabile no. 154. A.R.G. Gantner Verlag. Ruggell, Liechtenstein.

Miranda, B. E. C., Barreto, R. W., Crous, P. W., and Groenewald, J. Z. 2012. Pilidiella tibouchinase sp. nov. Associated with foliage blight of Tibouchina granulose (quaresmeira) in Brazil. IMA Fungus 3:1-7.

Nag Raj, T. R. 1993. Coelomycetous anamorphs with appendage-bearing conidia Mycologue Pub., Waterloo, Canada.

Nylander, J. A. A. 2004. MrModeltest 2.0. Evolutionary Biology Centre, Uppsala Univ., Sweden.

OIV. 2014. State of the Vitiviniculture World Market. International Organisation of Vine and Wine, Paris, France.

OIV. 2016. World Vitiviniculture Situation: OIV Statistical Report on World Vitiviniculture. International Organisation of Vine and Wine, Paris, France.

Page, R. D. M. 1996. TreeView: An application to display phylogenetic trees on personal computers. Comput. Appl. Biosci. 12:357-358.

Plantwise Knowledge Bank. 2012. Grapevine white rot. Plantwise Knowledge Bank, CABI, Wallingford, Oxfordshire, England. Retrieved 6 December 2015 from webl"^journal")

Quaedvlieg, W., Binder, M., Groenewald, J. Z., Summerell, B. A., Carnegie, A. J., Burgess, T. I., and Crous, P. W. 2014. Introducing the consolidated species concept to resolve species in the Teratosphaeriaceae. Persoonia 33:1-40.

Rajeshkumar, K. C., Hepat, R. P., Gaikwad, S. B., and Singh, S. K. 2011. Pilidiella crousii sp. nov. from the nothern Western Ghats, India. Mycotaxon 115:155-162.

Rehner, S. A., and Samuels, G. J. 1994. Taxonomy and phylogeny of Gliocladium analysed from nuclear large subunit ribosomal DNA sequences. Mycol. Res. 98:625-634.

Ronquist, F., and Huelsenbeck, J. P. 2003. MrBayes 3: Bayesian phylogenetic inference under mixed models. Bioinformatics 19:1572.

Rossman, A. Y., Farr, D. F., and Castlebury, L. A. 2007. A review of the phylogeny and biology of the Diaporthales. Mycoscience 48:135-144.

Samuels, G. J., Barr, M. E., and Lowen, R. 1993. Revision of Schizoparme (Diaporthales, Melanconidaceae). Mycotaxon 46:459-483.

Shao-Hua, L. 2001. Grape production in China. Pages 19-27 in: Grape Production in the Asia-Pacific Region. M. K. Papademetriou and F. J. Dent, eds. FAO, Rome, Italy.

Silvestro, D., and Michalak, I. 2010. RaxmlGUI: A graphical front-end for RAxML. Retrieved 29 September 2015, from webl"^journal").

Sutton, B. C. 1980. The Coelomycetes. Fungi imperfecti with pycnidia, acervuli and stromata. Commonwealth Mycological Institute, Kew, Surrey, UK.

Swofford, D. L. 2002. PAUP* 4.0: phylogenetic analysis using parsimony (* and other methods). Sinauer Associates, Sunderland.

Tiedemann, A. 1985. Untersuchungen zur Pathogenität des Erregers der Weißfäule (Coniella petrakii SUTT.) an Amerikaner-und Europärreben und Verbreitung und Bedeutung des Pilzes in den deutschen Weinbaugebieten. PhD Diss., Göttingen University, Germany.

Úrbez-Torres, J. R., Adams, P., Kamas, J., and Gubler, W. D. 2009. identification, incidence, and pathogenicity of fungal species associated with grapevine dieback in Texas. Am. J. Enol. Vitic. 60:4

Van Niekerk, J. M., Groenewald, J. Z. E., Verkley, G. J. M., Fourie, P. H., Wingfield, M. J., and Crous, P. W. 2004. Systematic reappraisal of Coniella and Pilidiella, with specific reference to species occurring on Eucalyptus and Vitis in South Africa. Mycol. Res. 108:283-303.

Verbeek, W. A. 1977. Plant Pathology. Annual Report of the Secretary for Agricultural Technical Services for the period 1 July 1975- 30 June 1976. Government Printer, Pretoria, South Africa.

Vilgalys, R., and Hester, M. 1990. Rapid genetic identification and mapping of enzymatically amplified ribosomal DNA from several Cryptococcus species. J. Bacteriol. 172:4238-4246.

Von Arx, J. A. 1973. Centraalbureau voor Schimmelcultures Baarn and Delft. Progress Reports 1972. Verhandelingen der Koninklijke Nederlandsche Akademie van Wetenschappen. Afdeling Natuurkunde 61:59-81.

Von Arx, J. A. 1981. The Genera of Fungi Sporulating in Pure Culture, 3rd Ed. J Cramer, Vaduz.

White, T. J., Bruns, T., Lee, S., and Taylor, J. W. 1990. Amplification and direct sequencing of fungal ribosomal RNA genes for phylogenetics. Pages 315-322 in: PCR protocols: A Guide to Methods and Applications. M. A. Innis, D. H. Gelfand, J. J. Sninsky, and T. J. White, eds. Academic, New York.

Wijayawardene, N. N., Hyde, K. D., Wanasinghe, D. N., Papizadeh, M. Goonasekara, I. D., Camporesi, E., Bhat, J. D., McKenzie, E. H. C., Phillips, A. J. L., Diederich, P., Tanaka, K., Li, W. J., Tangthirasunun, N., Phookamsak, R., Dai, D.-Q., Dissanayake, A. J., Weerakoon, G., Maharachchikumbura, S. S. N., Hashimoto, A., Matsumura, M., and Wang, Y. 2016. Taxonomy and phylogeny of dematiaceous coelomycetes. Fungal Divers. 77:1-316.

W. Y. Zhuang, ed. 2001. Higher Fungi of Tropical China. Mycotaxon, Ltd., Ithaca, NY. 